\title{
Innervation of the Pancreas by Neurons in the Gut
}

\author{
A. L. Kirchgessner and M. D. Gershon \\ Department of Anatomy and Cell Biology, Columbia University College of Physicians and Surgeons, New York, \\ New York 10032
}

Experiments were done in order to test the hypothesis that neurons in the bowel send axonal projections to the pancreas and can modify pancreatic activity. Pancreatic injections of the retrograde tracer, Fluoro-Gold, labeled neurons in the myenteric plexus of the antrum of the stomach and in the first $6 \mathrm{~cm}$ of the duodenum. This labeling was not due to the diffusion of Fluoro-Gold from the pancreas, because the injections did not label longitudinal muscle cells overlying labeled ganglia in the bowel or neurons in the phrenic nerve nucleus or nucleus ambiguous; nor were enteric neurons labeled if insufficient time was allotted for retrograde transport. More Fluoro-Gold labeled neurons were found in the stomach ( $9.2 \pm 0.9 /$ ganglion) than in the duodenum (3.8 $\pm 0.3 /$ ganglion; $p<0.001$ ). Neurons were found in myenteric ganglia of both duodenum and stomach that were doubly labeled by retrograde transport of Fluoro-Gold and anti-serotonin (5-HT) sera. In addition, thick bundles of 5-HT immunoreactive nerve trunks were found to run between the duodenum and the pancreas. Most 5-HT immunoreactive axons in the pancreas terminated in ganglia, although some fibers were also observed near acini, ducts, vessels, and islet cells. The B subunit of cholera toxin (B-CT) was microinjected into single myenteric ganglia in order to determine if axon terminals in the pancreas would become labeled by anterograde transport in the pancreas. B-CT labeled bundles of axons in the pancreatic stroma. Branches of these bundles entered the pancreatic parenchyma and varicose B-CT labeled terminal axons were found in pancreatic ganglia and in proximity to acinar and insulin immunoreactive cells. The intercalating fluorochrome 1, 1', dioctadecyl$3,3,3^{\prime}, 3^{\prime}$-tetramethylcarbocyanine perchlorate (Dil), which moves by lateral diffusion to outline entire cells, was introduced by microinjection into individual myenteric ganglia of fixed preparations. Fluorescence was seen in sequential observations to move away from the injected ganglion along connectives of the myenteric plexus. After about a month, neurons in ganglia at some distance from the injection site displayed Dil fluorescence as did nerve bundles that exited from the myenteric plexus and pierced the longitudinal muscle in the direction of the pancreas. Varicose Dil fluorescent terminal varicosities were also observed in the pancreas. These observations indicate that there is an extensive en-

\footnotetext{
Received Aug. 11, 1989; revised Oct. 25, 1989; accepted Nov. 6, 1989.

We wish to thank Ms. Marcy Adlersberg for her excellent technical assistance. This work was supported by NIH grants NS 12969, NS 15547, and NS 27645 and the BRSG grant to Columbia University.

Correspondence should be addressed to Dr. Annette Kirchgessner, Department of Anatomy and Cell Biology, Columbia University, College of P \& S, 630 West 168th Street, New York, NY 10032.

Copyright (c) 1990 Society for Neuroscience $0270-6474 / 90 / 051626-17 \$ 02.00 / 0$
}

tero-pancreatic innervation. The functional significance of this innervation was assessed by determining whether nerves from the gut can alter the activity of pancreatic neurons, islet, and acinar cells. Intrinsic enteric neural reflex pathways were activated in vitro by applying veratridine $(10.0 \mu \mathrm{M})$ to the duodenum. The cytochrome oxidase activity of neurons, islet, and acinar cells was demonstrated histochemically in attached segments of pancreas and measured by computer assisted video microdensitometry. Histochemically demonstrable cytochrome oxidase activity has been shown to increase in enteric neurons when the rate of discharge of action potentials is raised. Exposure of the duodenal mucosa to veratridine increased cytochrome oxidase activity in neurons of myenteric and pancreatic ganglia and in acinar and islet cells. This increase was prevented by TTX $(1.0 \mu \mathrm{M})$ or hexamethonium (10.0 $\mu \mathrm{m})$. Partial destruction of the duodenal myenteric plexus antagonized transmission of the effects of intraluminal veratridine to pancreatic neurons, acinar, or islet cells. These observations indicate that enteric neurons can influence the function of the exocrine and endocrine pancreas.

The enteric nervous system (ENS) is structurally and functionally different from other regions of the PNS (Gershon, 1981; Furness and Costa, 1987). With respect to structure, the enteric plexuses lack internal collagen (Bannerman et al., 1986; Gabella, 1987) and derive support for their neural elements from astrocyte-like glial cells that differ morphologically and developmentally from Schwann cells (Gabella, 1971; Jessen and Mirsky, 1980, 1983; Rothman et al., 1986). The ultrastructural appearance of the ENS, therefore, resembles that of the brain (Gabella, 1987). With respect to function, the ENS is unique among the divisions of the PNS in that it is able to mediate reflex activity in the absence of input from the brain or spinal cord (Trendelenburg, 1917; Gershon, 1981). Vagal axons innervate only a small subset of the neurons of the bowel (Kirchgessner and Gershon, 1989). The fact that the bowel can display reflexes, even in the absence of CNS input, further indicates that intrinsic primary afferent neurons are constituents of the ENS (Bülbring and Crema, 1958; Bülbring et al., 1958; Schofield, 1968; Gershon, 1981; Kirchgessner et al., 1988). The enteric ganglia are thus not simple parasympathetic relays, but components of a complex and independent nervous system (Langley, 1921). Moreover, most of the neurons of the ENS are interneurons involved in communication between the two ganglionated plexuses, between ganglia of the same plexus, and between neurons within a single ganglion (Takaki et al., 1985; Furness and Costa, 1987; Kirchgessner and Gershon, 1988).

In addition to its ability to act autonomously to mediate reflex activity, the ENS is able to influence those signals it does receive 
from the CNS via sympathetic postganglionic neurons. Enteric neurons project centripetally out of the bowel to modify transmission through prevertebral sympathetic ganglia (Ungváry and Léránth, 1970; Szurszewski and Weems, 1976). The projections of the ENS to prevertebral ganglia have been extensively studied using immunocytochemistry, retrograde tracers, and electrophysiology (Dalsgaard et al., 1983; Lee et al., 1986; Furness and Costa, 1987). Myenteric neurons in the rectum have also been shown to send axons directly into the spinal cord (DoerfflerMelly and Neuhuber, 1988). The existence of extensive projections of neurons out of the enteric plexuses raises the question of whether the ENS innervates other organs.

The possibility that the ENS might innervate the accessory organs of digestion seems especially strong since these organs arise as outgrowths of the gastrointestinal tract during fetal life. The ganglionated plexus of the gallbladder has recently been demonstrated to resemble the submucosal plexus of the gut and to be innervated by neurons the cell bodies of which are located in the myenteric plexus of the duodenum (Mawe and Gershon, 1989). There is also evidence that suggests that enteric neurons may project to the pancreas. For example, gross anatomical dissections have revealed large numbers of nerves apparently running between the duodenum and the pancreas (Tiscornia, 1977). That such nerves exist has been confirmed by histological observations (Anglade et al., 1987). Furthermore, severing of neural connections between the gut and the pancreas abolishes the release of pancreatic polypeptide from the pancreas that is elicited by gastric distension (Poulson et al., 1983). The ENS, moreover, may also affect insulin secretion. It has been shown that oral glucose is a more effective stimulant of insulin secretion than is an equivalent amount of glucose given systemically (McIntyre et al., 1964). The term "entero-insular axis" was introduced to describe the regulatory mechanisms existing between the gut and islets (Unger and Eisentraut, 1969). It is true that insulin secretion is influenced by circulating gastrointestinal hormones, the main insulinotropic hormone candidates being cholecystokinin (CCK), gastrin, and gastric inhibitory polypeptide (GIP; Holst et al., 1980); however, the mechanism of enteric control of islet cell function has not been completely elucidated, and may involve a neural as well as a hormonal component.

The current study was undertaken to determine whether enteric neurons project to the pancreas. The retrograde tracer, Fluoro-Gold (Schmued and Fallon, 1986), was injected into the pancreas and the cell bodies of neurons were examined in the duodenum and stomach. In addition, the $B$ subunit of cholera toxin (B-CT) was introduced into single myenteric ganglia with a micropipette and a search was made for terminals labeled by anterograde transport in the pancreas. The lipid soluble dye ( 1 , $l^{\prime}$, dioctadecyl-3,3,3',3'-tetramethylcarbocyanine perchlorate (Dil), which inserts into plasma membranes and outlines entire cells by lateral diffusion (Honig and IIume, 1986; Godement et al., 1987), was also microinjected into individual myenteric ganglia. For studies with Dil, fixed tissue was utilized. Since serotonergic axons but not cell bodies have been found in the pancreas (Nunez et al., 1980; Koevary et al., 1980, 1983), while serotonergic neurons reside in the ENS (Furness and Costa, 1987; Gershon et al., 1989), the hypothesis that pancreatic serotonergic neurites are projections of enteric neurons was tested. Finally, in order to evaluate the possible functional significance of an enteric innervation of the pancreas, the ability of nerves from the gut to alter the activity of pancreatic neurons, islet, and acinar cells was assessed. For this purpose enteric neurons were stimulated in vitro by luminal application of veratridine, and the metabolic activity of neurons, islet, and acinar cells was determined in attached segments of pancreas by measuring their cytochrome oxidase activity. Cytochrome oxidase has been shown to be an endogenous marker for neuronal activity (WongRiley, 1989). When the rate of discharge of action potentials is raised, even in vitro, this increase is rapidly and consistently reflected in an increased level of histochemically demonstrable cytochrome oxidase activity in the stimulated neurons (Mawe and Gershon, 1986).

\section{Materials and Methods}

Injection of tracers in vivo. Eight adult female rats (200-250 gm) were anesthetized with an intraperitoneal injection of pentobartital $(50 \mathrm{mg} /$ $\mathrm{kg}$ ). The animal's abdominal area was shaved and a midline incision through the skin and linea alba was made from the xiphoid process to a point about $1 \mathrm{~cm}$ below the umbilicus. A self-retaining retractor was inserted and expanded to provide wide exposure of the upper abdominal organs. From this point onward all procedures were monitored with an operating microscope. In order to make injections as reproducible as possible, the pancreas was divided into three sections, two of which, the head and tail, were injected. The head was defined as that pancreatic rcgion enclosed by the loop of the duodenum, while the tail comprised the segment of the pancreas in contact with the spleen. The intervening zone, in the bed of the stomach, was not injected, so that the injection sites were widely separated from one another and were as far as possible from the bowel. Fluoro-Gold (4\% in isotonic saline; Fluorochrome, Inc., Englewood, $\mathrm{CO}$ ) was injected in a volume of $1.0 \mu \mathrm{l} /$ injection site. Three widely spaced injections were made in the head or tail segments of the pancreas with a glass micropipette ( $40 \mu \mathrm{m}$ tip diameter), attached by means of sealing wax to the needle of a $50 \mu \mathrm{l}$ Hamilton syringe. Injections were accomplished by carefully inserting the tip of the micropipette 5$8 \mathrm{~mm}$ into the pancreatic tissue. Visible pancreatic blood vessels or ducts were avoided. Following each injection, the micropipette was left in place for $1 \mathrm{~min}$ so that back-pressure from the injected bolus of fluid would not force tracer to leak out of the tissue along the injection track. In order to prevent direct spread of injected tracer to the bowel, the duodenum and stomach were covered with Parafilm during the injections, and each injection site was swabbed using saline-soaked cotton swabs upon removal of the injecting micropipette. In addition, the spread of Fluoro-Gold, which is yellow, was followed visually. The rats were allowed to survive for $3-5$ d postoperatively to allow time for transport of the tracer.

Controls. In order to be certain that direct spread of Fluoro-Gold to the bowel had not occurred following its injection into the pancreas, all cases in which the enteric musculature was observed to be fluorescent were eliminated from the study. Moreover, additional controls were examined in which inadequate time $(2-4 \mathrm{hr})$ was allotted for retrograde transport between pancreas and bowel. In 2 additional animals, injections of the tracer were deliberately placed on the surface of the pancreas near the duodenum so as to evaluate the labeling that might be produced in duodenal or gastric ganglia by direct spread of the tracer to the gut.

Injection of anterograde tracer in vitro. Male guinea pigs (500 gm) were stunned by a blow to the head and exsanguinated. This procedure has been approved by the Animal Care and Use Committee of Columbia University. The duodenum with attached pancreas was removed and transferred to a beaker of oxygenated Krebs solution at room temperature. The myenteric plexus and underlying longitudinal muscle were dissected from the wall of the bowel as previously described (Kirchgessner and Gershon, 1988), except that pancreatic attachments were left intact. The resulting myenteric plexus-pancreatic preparation was stretched flat in an organ chamber filled with oxygenated Krebs solution. The organ chamber was then placed on the stage of an inverted microscope and the tissue was superfused with oxygenated Krebs solution $(10-15 \mathrm{ml} / \mathrm{min})$ at $37^{\circ} \mathrm{C}$. Individual myenteric ganglia were visualized using differential interference contrast optics and injected through a glass micropipette with the B subunit of cholera toxin conjugated to fluorescein isothiocyanate (1.0\% [B-CT-FITC]; List Biological Laboratories, Campbell, CA). Three or 4 ganglia were injected in each preparation. Injections were made with pressure $(8 \mathrm{psi})$ by applying $100 \mathrm{msec}$ pulses of $\mathrm{N}_{2}$ at a frequency of $1.0 \mathrm{~Hz}$ for $5 \mathrm{~min}$. The progress of injection was monitored by visualizing the fluorescence of the tracer using the " $\mathrm{B} 2 \mathrm{~A}$ " (FITC) cube of the microscope. Following injection, tissues were in- 
cubated with constant agitation in oxygenated Krebs solution at $37^{\circ} \mathrm{C}$ for a further $4 \mathrm{hr}$.

Fixation and tissue processing. Rats were killed with an overdose of sodium pentobarbital $(100 \mathrm{mg} / \mathrm{kg})$ and perfused transcardially with 50 $\mathrm{ml}$ of $0.9 \%$ saline. The stomach, small intestine, and pancreas were removed from the animals while saline was still being perfused and placed into a beaker of oxygenated Krebs solution $\left(37^{\circ} \mathrm{C}\right)$. The brain was then fixed by perfusion with $200 \mathrm{ml}$ of $4 \%$ (wt/vol) formaldehyde (from paraformaldehyde) in $0.1 \mathrm{M}$ phosphate buffer ( $\mathrm{pH} 7.4)$. The pancreas and segments taken from the gastrointestinal tract were maintained in oxygenated Krebs solution for $1-2 \mathrm{hr}\left(37^{\circ} \mathrm{C}\right)$. Some of these tissues were exposed to 6-hydroxydopamine ([6-OHDA] $0.5 \mathrm{~mm}$; Sigma Chemical Co.) for $2 \mathrm{hr}$ in order to lesion noradrenergic axons (Costa et al., 1982; Furness and Costa, 1982). Following a $10 \mathrm{~min}$ wash in fresh Krebs solution, these tissues were incubated with 5,7-dihydroxytryptamine ([5,7-DHT] $50 \mu \mathrm{M}$; Sigma) for $30 \mathrm{~min}$ in order to enhance the immunocytochemical visualization of 5-HT in intestinal neurons (Costa et al., 1982; Furness and Costa, 1982). After the period of incubation in the presence or absence of 6-OHDA and 5,7-DHT, the duodenum, stomach (antrum, corpus, fundus), and pancreas were then fixed (as above) for $3 \mathrm{hr}$. Segments of pancreas to be frozen sectioned were cryoprotected by incubation overnight in PBS containing 30\% (wt/vol) sucrose. This tissue was then frozen in liquid $\mathrm{N}_{2}$ and sectioned at 20 $\mu \mathrm{m}$ using a cryostat-microtome. Serial sections of the hindbrain were cut in the coronal plane at $50 \mu \mathrm{m}$ with a Vibratome (Oxford Instruments).

Preparation of whole mounts. Whole mounts containing either the longitudinal muscle and myenteric plexus or the submucosa were prepared from the stomach and duodenum as previously described (Kirchgessner and Gershon, 1988, 1989). In some experiments the longitudinal muscle with adherent myenteric plexus of the duodenum was prepared with the pancreatic attachment left intact. This tissue was used for the histochemical demonstration of AChE activity by the method of Karnovsky and Roots (1964) in order to visualize enteric-pancreatic neural projections in whole mounts. For this purpose preparations were first permeabilized by incubation overnight with Triton X-100 (1.0\%) at $4^{\circ} \mathrm{C}$. Following the $\mathrm{AChE}$ procedure, the specimens were dehydrated and rendered transparent with methyl salicylate.

Tracing neuronal projections with Dil. The pancreatic projections of enteric neurons were also examined in fixed rat tissue using the carbocyanine dye Dil (2.5\% in $100 \%$ ethanol; Molecular Probes) as an anterograde tracer. Individual myenteric ganglia in dissected laminar preparations to which the head of the pancreas was left attached were injected with Dil as described above for B-CT-FITC. The injected material was stored at room temperature in a solution containing $4 \%$ formaldehyde for 1-2 months to allow the dye to diffuse throughout labeled neurons. Tissues were examined at weekly intervals to monitor progress of the dye. Dil was visualized by using the " $\mathrm{N}_{2}$ " filter cube (exciting filter BP 530-560; dichroic mirror RKP 580; barrier filter LP 580). Since Dil injected material cannot be frozen, only whole mounts of the pancreas were investigated.

Visualization of tracers and neurochemical characterization of neurons by immunocytochemistry. Preparations from experiments in which Fluoro-Gold was injected into the pancreas were mounted on gelatin coated glass slides and coverslipped with a nonfluorescent mounting medium. Fluoro-Gold was visualized by vertical fluorescence microscopy using the "A" cube (excitation light 340-380 nm; dichroic mirror cutoff 400 $\mathrm{nm}$; suppression filter $340 \mathrm{~nm}$ ) of a Leitz fluorescence microscope. Serotonergic neurons and their processes were simultaneously examined, first by identifying the native fluorescence of 5,7-DHT (Sandell and Masland, 1986), and then by immunocytochemistry with affinity purified rabbit polyclonal antibodies to $5-\mathrm{HT}$. These antibodies have previously been characterized (Tamir et al., 1989) and can be absorbed by a $\beta$-carboline (the reaction product formed by 5 -HT and formaldehyde) coupled to BSA. For immunocytochemistry, enteric tissue was incubated with $4 \%$ normal goat serum in $0.1 \mathrm{M}$ PBS for $30 \mathrm{~min}$, exposed overnight to the primary antibodies against 5-HT (diluted 1:200), washed in PBS, then incubated for $3 \mathrm{hr}$ with affinity purified biotinylated goat anti-rabbit secondary antibodies (diluted 1:400; Kirkegaard and Perry, Gaithersburg, MD) and finally treated for $1 \mathrm{hr}$ with avidin coupled to fluorescein isothiocyanate (FITC, diluted 1:200; Vector Laboratories). Since labeled avidin was found to bind to a number of structures in the pancreas in the absence of primary or secondary antibodies, the avidinbiotin technique was not suitable for immunocytochemical studies of the pancreas. Accordingly, pancreatic sites of 5-HT immunoreactivity were visualized by using affinity purified FITC- or tetramethyl rhodamine isothiocyanate (TRITC)-labeled mouse antirabbit secondary antibodies (diluted 1:80; Jackson Immuno Research Laboratories). B-CT was identified immunocytochemically in order to maximize sensitivity of the method for detection of the tracer. For this purpose frozen sections of pancreatic tissue were exposed to goat anti-CT serum (diluted 1:500; List Biological Laboratories). Sites of bound antibody were visualized with a rabbit antigoat secondary antibody labeled with FITC (Kirkegaard and Perry). For demonstration of the immunoreactivity of type B monoamine oxidase (MAO-B), a monospecific sheep anti-MAO-B serum (diluted 1:400; Pintar et al., 1983) was used. Secondary antibodies used to visualize sites of MAO-B immunoreactivity were FITC-labeled swine antisheep (diluted 1:80). In some experiments insulin immunoreactive cells were located in the pancreas using a guinea pig anti-insulin serum (diluted 1:500; Milab, Milamo, Sweden). This antibody was visualized with a TRITC-labeled goat anti-guinea pig antibody (Kirkegaard and Perry). Triton X-100 (1\%), to enhance penetration of the immunoreagents, was added to the first incubating solution and to all immune reagents. After washing in PBS, the tissues were coverslipped with $50 \%$ glycerol in $0.1 \mathrm{~m}$ sodium carbonate buffer, $\mathrm{pH} 9.0$, containing $0.4 \mathrm{mg} / \mathrm{ml}$ of p-phenylenediamine (Johnson and de C. Nogueira Araujo, 1981). FITC fluorescence was visualized by vertical fluorescence microscopy using a Leitz " $L_{2}$ " narrow band filter cube (exciting filter BP 450-490; dichroic mirror RKP 510, barrier filter BP 525/20). TRITC fluorescence was visualized using a I eitz " $\mathrm{N}_{2}$ " filter cube (see above). There is no cross detection between the FITC (" $\mathrm{L}_{2}$ ") and TRITC ("N $\mathrm{N}_{2}$ ") selective dichroic mirror-filter cubes.

Effect of enteric veratridine on pancreatic cytochrome oxidase activity. Segments of duodenum ( $2 \mathrm{~cm}$ in length), to which the pancreas was left attached, were removed from adult male guinea pigs. The lumen of the bowel was filled with $200 \mu \mathrm{l}$ of experimental or control solutions (made up in Krebs), sutured shut at both ends, and transferred, together with the attached pancreas, to oxygenated Krebs solution at $37^{\circ} \mathrm{C}$. The experimental solution contained veratridine $(10.0 \mu \mathrm{M})$, while the controls consisted of veratridine $(10.0 \mu \mathrm{M})$ plus TTX $(1.0 \mu \mathrm{M})$ or Krebs solution alone. In additional experiments hexamethonium $(10.0 \mu \mathrm{M})$ was added to the incubating medium outside the gut. A final control was done by partially dissecting the longitudinal muscle with attached myenteric plexus from the wall of the duodenum (myectomy) prior to incubation with veratridine in the lumen. When myectomy was performed, care was taken not to damage the attachment of pancreas to the bowel. The preparations were incubated for $3 \mathrm{hr}$, the lumen was then opened, and the tissue was fixed as described above. Following fixation, the pancreas was removed, cryoprotected, and frozen sections were cut as described previously. The wall of the duodenum was dissected into layers and the resulting laminar preparations were examined as whole mounts. $\mathrm{Cy}$ tochrome oxidase activity was demonstrated histochemically in sections of pancreas or whole mounts of duodenum as described by Mawe and Gershon (1986). Computer assisted video microdensitometry (Imaging Research Inc., St. Catherines, Ontario) was used to examine the density of the cytochrome oxidase reaction product in enteric and pancreatic neurons. Additional measurements were made on islet and acinar cells. For measurements of density a window with an area about half that of a cell under analysis was centered over a region of the cytoplasm that did not include the nucleus. Background measurements were taken from adjacent tissue and were subtracted from the density of the measured cells.

\section{Results}

Visualization of nerves between gut and pancreas

Ganglia and nerves were visualized in the duodenum and pancreas in cleared preparations in which AChE activity had been histochemically demonstrated. The ganglia and connectives of the myenteric plexus of the duodenum as well as intrinsic ganglia within the pancreas (Fig. 1, $A, B$ ) display intense AChE activity; thus, following the histochemical demonstration of $\mathrm{AChE}$, the distribution of ncural clements is well revealed in cleared whole mounts of these organs. Thick nerve bundles were found to extend between the duodenum and the pancreas. These bundles could be seen to merge in the duodenum with the myenteric plexus and in the pancreas with nerves entering and exiting 

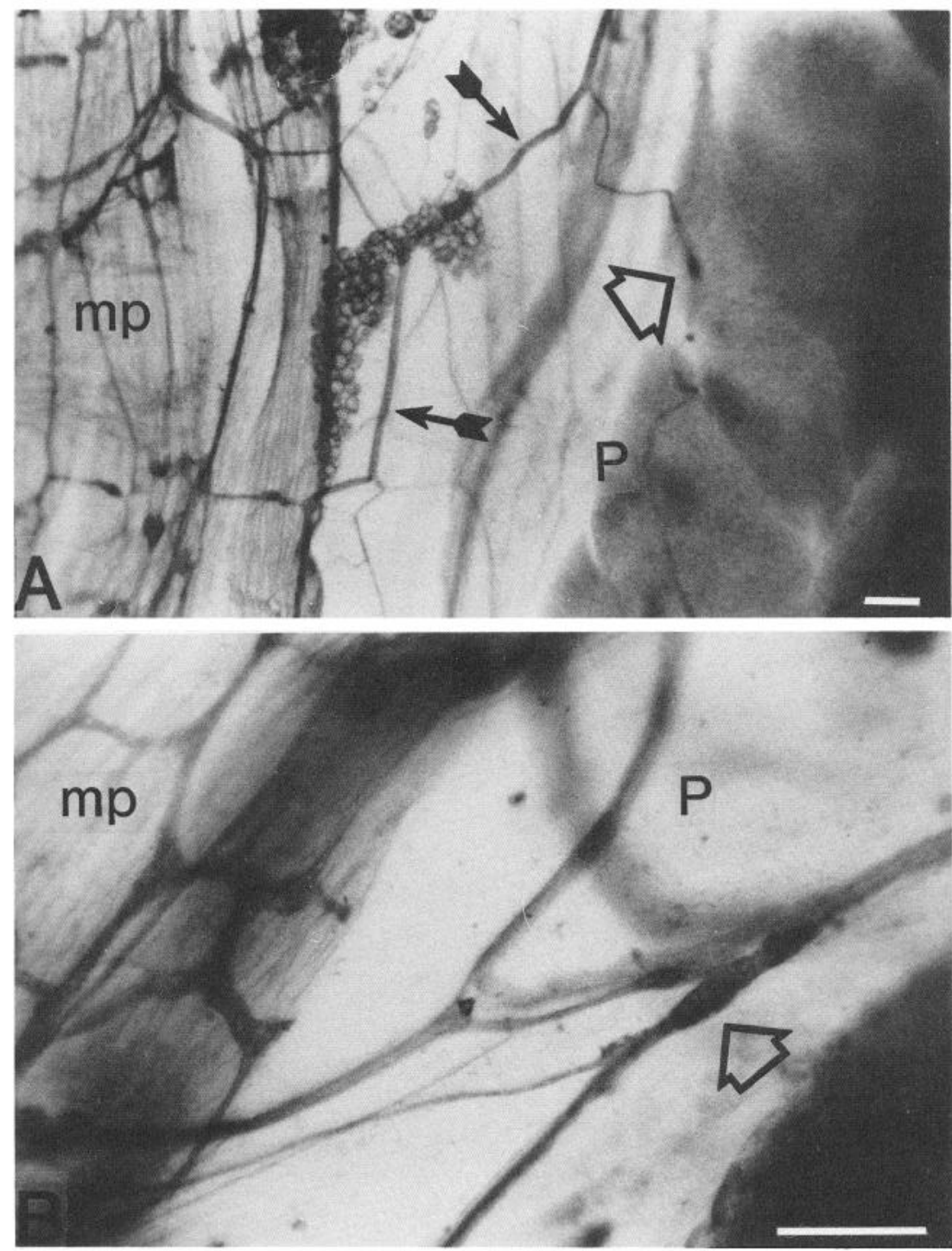

Figure 1. Neural connections between the duodenum and pancreas are revealed by the histochemical demonstration of AChE activity. The longitudinal muscle with adherent myenteric plexus has been dissected from the duodenum, leaving intact the connective tissue between the bowel and pancreas. The entire preparation was processed as a whole mount and made transparent by dehydration and clearing with methyl salicylate. The regular pattern of the ganglia and connectives of the myenteric plexus $(\mathrm{mp})$ can readily be seen. Coarse bundles of nerve fibers $(\rightarrow)$, continuous in the duodenum with the myenteric plexus $(A)$ extend across the intervening connective tissue $(A, B)$ to enter the pancreas $(P)$, where they can be seen to enter pancreatic ganglia $(\Delta)$. Scale bars, $50 \mu \mathrm{m}$. intrinsic ganglia (Fig. 1, $A, B$ ). These observations thus confirm the existence of nerves between the gut and pancreas and reveal that these nerves interconnect the myenteric plexus and pancreatic ganglia.

\section{Injection of Fluoro-Gold into the pancreas}

Fluoro-Gold was injected into the head or tail regions of the pancreas. The individual injection sites, which could readily be visualized in whole mounts of pancreatic tissue, were relatively confined (Fig. $2 A$ ). Sections cut through these sites revealed that the injected Fluoro-Gold was mainly taken up by exocrine cells (Fig. $2 B$ ), although occasional injections also entered islets. Both nerve fibers (Fig. $2 C$ ) and neuronal perikarya within intrapancreatic ganglia (Fig. 2D) outside the boundaries of the injection sites were labeled by Fluoro-Gold. The labeled nerve fibers appeared to travel in the connective tissue surrounding pancreatic ducts. The ducts themselves, as well as intrapancreatic blood vessels, were not fluorescent except within the injection sites; moreover, there was no fluorescence in the connective tissue surrounding the pancreas or in the adventitia or muscle of the duodenum and stomach.
The labeling by Fluoro-Gold of intrapancreatic nerve fibers and cell bodies suggested that the tracer had been taken up by nerve terminals within the organ and that it was subject to retrograde transport. Intrapancreatic projections, however, appeared to be very short. In order to confirm that pancreatic injections of Fluoro-Gold specifically labeled neurons by retrograde transport, a known source of pancreatic nerve terminals, the dorsal motor nucleus of the vagus (DMX) was examined. Fluoro-Gold labeled nerve cell bodies were found in the medial portion of the DMX as previously found by others (Fox and Powley, 1986; Rinaman and Miselis, 1987). No labeled cells were seen in the nucleus ambiguous or in the ventral horn of the cervical spinal cord (studied as far caudally as $\mathrm{C}_{4}$ ). These observations indicated that the injections had not extended out of the pancreas to reach vagus nerve terminals in the gastroesophageal junction or phrenic nerve fibers in the diaphragm.

Following pancreatic injections of Fluoro-Gold, many labeled neurons were found in the myenteric plexus of the stomach (Fig. $3 A$ ), proximal (Fig. $3 B$ ), and distal duodenum (Fig. $3 C$ ). Labeled neurons occurred in clusters (Fig. $3 A$ ) or as solitary neurons (Fig. $3 C$ ) surrounded by unlabeled cells. Some neurons were 

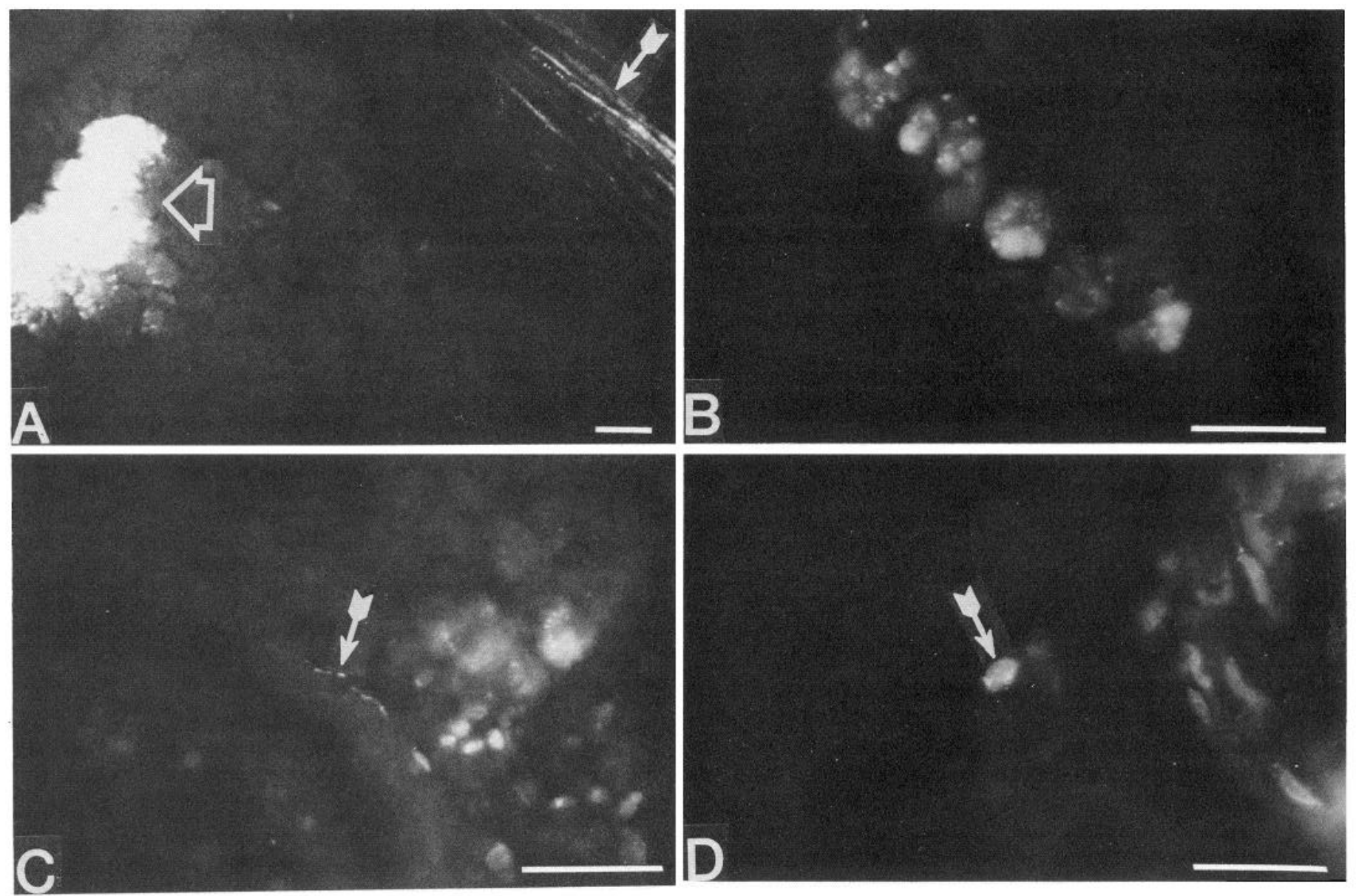

Figure 2. Following its injection into the pancreatic parenchyma, Fluoro-Gold is taken up by acinar cells and nerve fibers near the injection site. Fluoro-Gold is also transported to distant intrapancreatic ganglia, where it labels neuronal cell bodies. $A$, A whole mount of pancreas. Acini are fluorescent at the injection site $(\rightarrow)$, which is relatively confined. Fluorescent axons $(\rightarrow)$ can be seen in the stroma. Note the absence of fluorescence in the intervening tissue. $B$, A thin frozen section of the pancreas confirming that acini are fluorescent. $C$, A varicose Fluoro-Gold labeled axon $(\rightarrow)$ leads away from fluorescent acini, which mark the location of an injection site. $D$, A single fluorescent neuronal cell body $(\rightarrow)$ can be seen in a pancreatic ganglion. Scale bars, $50 \mu \mathrm{m}$.

more heavily labeled than others. Within the labeled neurons, Fluoro-Gold was seen in discrete intracytoplasmic fluorescent granules (Fig. 3, $A-D$ ). These fluorescent granules were most numerous in cell bodies, but often extended into processes that were oriented perpendicular to the proximo-distal axis of the bowel. In neither the stomach nor the duodenum could any labeled cells be seen in the submucosal plexus. Within the stomach, cells labeled with Fluoro-Gold were observed in myenteric ganglia in both the antral and corpal regions. No fluorescence was detected in the muscle or connective tissue surrounding ganglia that contained labeled neurons, nor did glial cells fluoresce within these ganglia. This pattern suggests that the observed labeling of neurons was due to axonal transport of Fluoro-Gold and not to diffusion of the tracer from the pancreas, which would have exposed muscle, connective tissue, and glia as well as neurons to Fluoro-Gold. As a control, similar injections of Fluoro-Gold were placed into the head of the pancreas and $2-4 \mathrm{hr}$ later the stomach and duodenum were examined. No fluorescent neurons were observed (data not illustrated). From 2 to $4 \mathrm{hr}$ is insufficient time for the retrograde transport of Fluoro-Gold from the pancreas to the bowel. The absence of labeling in the gut after this short survival period thus supports the conclusion that retrograde transport of Fluoro-Gold is responsible for the labeling of cells observed in the myenteric plexus 3-5 d after the pancreatic injection of the tracer. As a further control, $3 \mu \mathrm{l}$ of Fluoro-Gold were injected onto the peritoneal reflection covering the pancreas and the bowel was examined 3-5 d later. After these injections longitudinal muscle fibers became fluorescent (data not illustrated), as did the glia of the enteric plexuses. This pattern of labeling by direct spread of tracer into the bowel was thus quite different from that obtained by intrapancreatic injection of Fluoro-Gold and again supports the idea that the intrapancreatic injections labeled myenteric neurons by retrograde transport.

Following the injection of Fluoro-Gold into the head of the pancreas, more neurons per ganglion were found to be labeled in the stomach $(9.2 \pm 0.9)$ than in the duodenum $(3.8 \pm 0.3$; $p<0.001$ ) (Fig. 4). This difference between stomach and duodenum was even more striking when injections of Fluoro-Gold were made into the tail of the pancreas, because tail injections labeled more gastric neurons per ganglion $(14.2 \pm 2.1 ; p<0.05)$ than did injections placed in the head of the organ and injections of Fluoro-Gold into the tail of the pancreas labeled very few duodenal neurons. Within the duodenum, following injections 


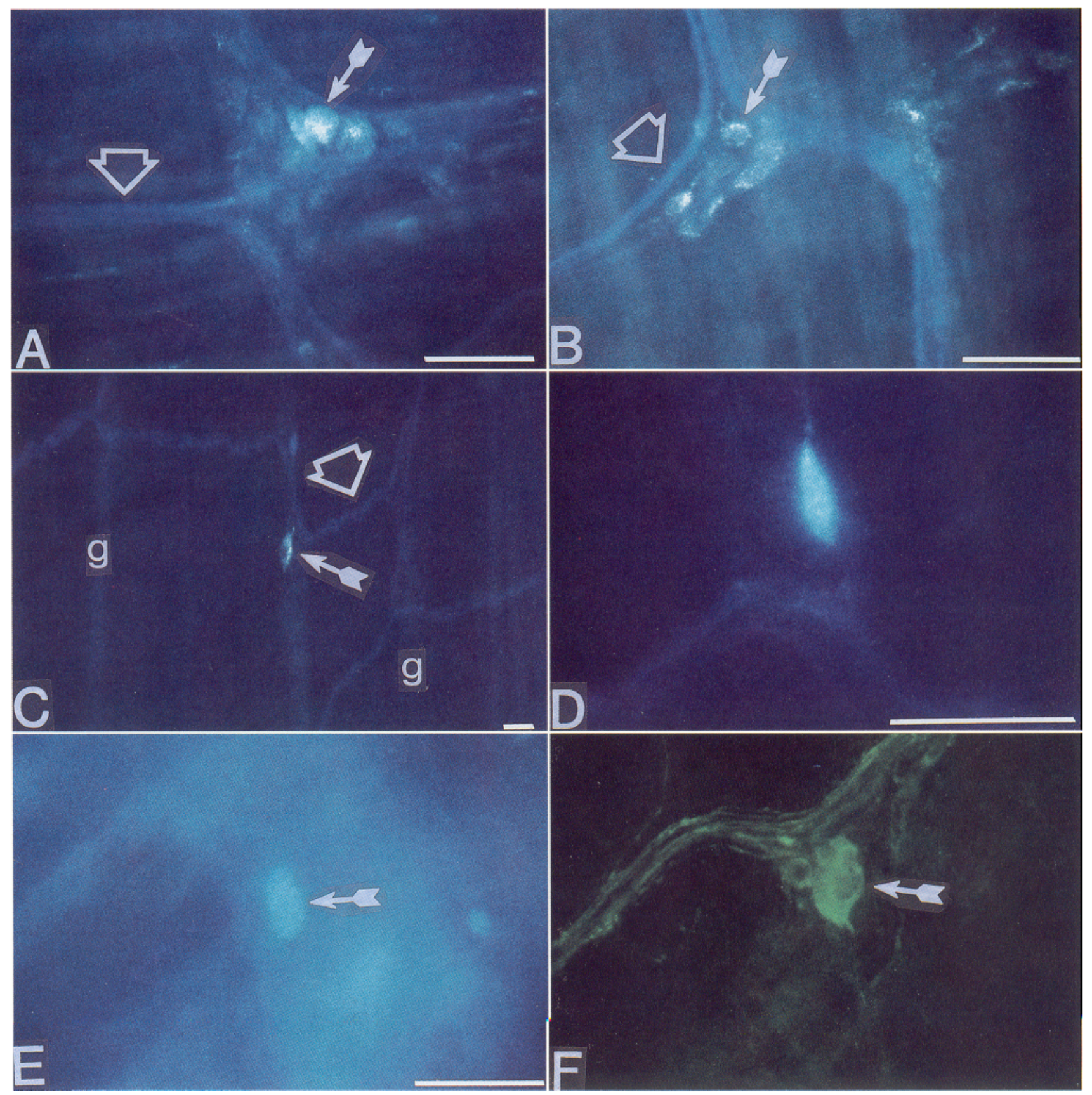

Figure 3. Following its injection into the pancreas, Fluoro-Gold labels the cell bodies of neurons in the myenteric plexus of the stomach and duodenum. A subset of these neurons is triply labeled by uptake of 5,7-DHT, and antisera to 5-HT. The longitudinal muscle with adherent myenteric plexus was dissected from the gastric antrum and duodenum, incubated with 6-OHDA and 5,7-DHT, and viewed as whole mounts. A, A cluster of Fluoro-Gold-labeled neurons $(\rightarrow)$ in a myenteric ganglion in the gastric antrum. Fibers that display the fluorescence of 5,7-DHT in connectives $(\Delta)$ pass through the ganglion. B. Fluoro-Gold labeled neurons $(\rightarrow)$ in a myenteric ganglion in the proximal duodenum. Bundles of fibers that display the fluorescence of 5,7-DHT in connectives $(\rightarrow)$ pass through the ganglion. $C$, A single Fluoro-Gold labeled neuron $(\rightarrow)$ in a myenteric ganglion in the distal duodenum. The outline of the myenteric plexus $(\rightarrow)$ is visible because it contains fibers that display the fluorescence of 5,7DHT. D, A solitary neuron doubly labeled by Fluoro-Gold and 5,7-DHT in the myenteric plexus of the duodenum. The presence of fluorescent granules (Fluoro-Gold) in a diffuse blue background (5,7-DHT) can be recognized. $E, F$, The same neuron is illustrated in both figures. This neuron is labeled by uptake of 5,7-DHT and Fluoro-Gold ( $E$, "A" filter cube) and displays 5-HT immunoreactivity $\left(F\right.$, " $L_{2}$ " filter cube). Scale bars, $50 \mu$ m.

of Fluoro-Gold into the head of the pancreas, the labeled neurons were confined to the $6 \mathrm{~cm}$ immediately distal to the pyloric sphincter (Fig. 5). Within this region the mean density of labeled neurons was significantly higher proximally $(4.3 \pm 0.3$ neurons/ ganglion) than distally $(2.5 \pm 0.5 ; p<0.003)$. These observa- tions suggest that myenteric neurons in both stomach and duodenum project to both head and tail of the pancreas; however, more gastric than duodenal neurons project to the pancreas, and the duodenal projections are derived mainly from the first segment of the small bowel. 


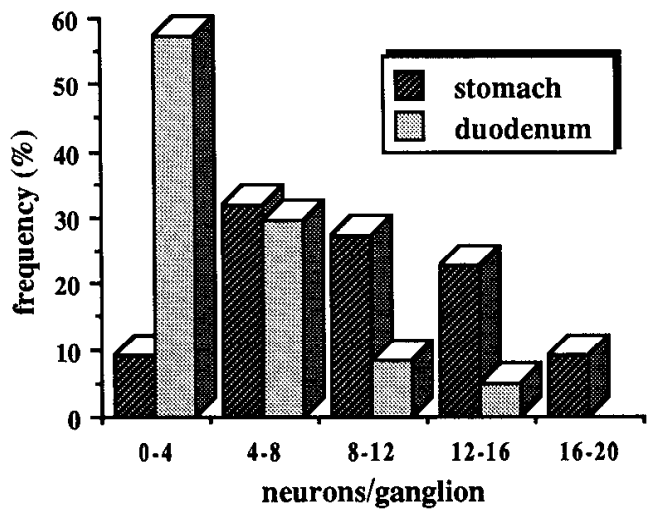

Figure 4. A frequency distribution histogram showing the number of Fluoro-Gold labeled neurons/ganglion in the stomach and duodenum. Ganglia with larger numbers of labeled neurons are more frequent in the stomach than the duodenum.

\section{5-HT in Fluoro-Gold labeled enteric neurons}

Two methods were used to locate serotonergic neurons in the bowel of animals whose pancreas had been injected with FluoroGold. In some animals the gut was incubated with 5,7-DHT and 6-OHDA. Serotonergic neurons, which concentrate 5,7DHT, were identified by the native fluorescence of this neurotoxin. Serotonergic neurons were also visualized immunocytochemically with antibodies to 5-HT. As previously reported (Kirchgessner and Gershon, 1989), more serotonergic neurons were found in the stomach (1.15 neurons/ganglion) than in the duodenum ( 0.18 neurons/ganglion). Serotonergic neuronal perikarya were extremely rare in the first $4 \mathrm{~cm}$ of the duodenum ( 0.03 neurons/ganglion), although the myenteric plexus in this region, as in the remainder of the bowel, contained many serotonergic axons in interganglionic fiber tracts (Fig. 3, $B, C$ ). In both the stomach and the duodenum serotonergic fibers were found to encircle neurons that were labeled by Fluoro-Gold (data not illustrated). In addition, in both the stomach and the duodenum many of the serotonergic neurons were labeled by Fluoro-Gold (Fig. 3, $D-F$ ). Such neurons displayed both Fluoro-Gold and 5,7-DHT fluorescence (Fig. $3 D$ ) and could also be triply labeled by subsequent exposure to anti-5-HT sera (compare Fig. 3, E and $F$ ). Following an injection of Fluoro-Gold into the tail of the pancreas, for example, $14.2 \pm 2.1$ neurons/ganglion in the myenteric plexus of the antrum were labeled by Fluoro-Gold; $0.8 \pm 0.2$ neurons/ganglion were triply labeled by $5,7-\mathrm{DHT}$ and anti-5-HT antibodies. Although this serotonergic population was a relatively small subset of the neurons that contained Fluoro-Gold, it represented a large proportion $(21 / 25)$ of the serotonergic perikarya in those ganglia that contained Fluoro-Gold labeled cells. These observations suggest that the majority of gastric neurons that project to the pancreas are not serotonergic, but the majority of gastric serotonergic neurons project to the pancreas.

\section{Distribution of 5-HT immunoreactive axons in the pancreas}

In the duodenum, large bundles of nonvaricose serotonergic fibers were observed to leave the myenteric plexus and to pass through the longitudinal muscle to reach the connective tissue between the pancreas and duodenum. The appearance of these axons was markedly different from that of the 5-HT immuno-

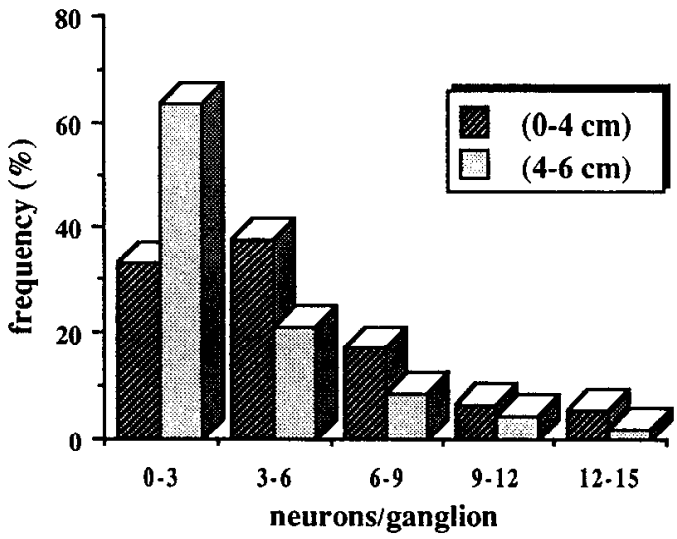

Figure 5. A frequency distribution histogram showing the number of Fluoro-Gold labeled neurons/ganglion in proximal and distal regions of the duodenum. Ganglia with larger numbers of labeled neurons are more frequent in the proximal segment of the duodenum.

reactive axons in ganglia, which are varicose (Fig. $6, A, B$ ). These bundles of serotonergic fibers appeared to enter the pancreas. Within the pancreas 5-HT immunoreactivity was not found in any neuronal cell bodies; however, 5-HT immunoreactive axons were found. In rat pancreas they were seen near blood vessels (Fig. $7 A$ ), while in guinea pig pancreas the serotonergic axons were found in nonvaricose bundles in the connective tissue surrounding ducts and acini (Fig. $7, B, C$ ). The distribution of 5-HT immunoreactive nerve fibers was nonuniform; fibers tended to be concentrated near a relatively small subset of acini. Pancreatic ganglia were located by demonstrating MAO-B immunoreactivity, and 5-HT immunoreactivity was simultaneously visualized in the same tissue sections by using a contrasting fluorophore. Varicose 5-HT-immunoreactive terminal axons were observed in most pancreatic ganglia, where they contacted a subset of MAO-B immunoreactive neurons (Fig. 8, $A, B$ ). Although the most common location of varicose 5 -HT immunoreactive terminal axons was in ganglia, rare 5-HT immunoreactive nerve fibers were also seen in islets (Fig. 8C). In the guinea pig a subset of islet cells themselves showed 5-HT immunofluorescence (Fig. $8 D$ ). The pancreatic stroma also contained small isolated 5-HT immunoreactive cells, the nature of which was not determined (Fig. 7B).

\section{Tracing projections of enteric neurons with Dil and B-CT}

Microinjection of the intercalating fluorescent probe Dil was used to confirm (by a technique that does not rely on retrograde axonal transport) that myenteric neurons project to the pancreas. One to 2 months following injection, Dil was found to have moved out of the injected ganglion along connectives of the myenteric plexus (Fig. 9A). Many cells became fluorescent in neighboring ganglia. In addition, Dil fluorescence was also seen in fibcr tracts extending out of the plane of the myenteric plexus in the direction of the pancreas. Nonvaricose Dil labeled axons were found in the connective tissue between the gut and the pancreas (Fig. 9B). Within the pancreas, Dil fluorescence was found in varicose axons (Fig. $9 C$ ) and in complex terminal arborizations in the pancreatic parenchyma (Fig. 9, $D-F$ ). These observations thus confirm that neurons of the myenteric plexus innervate targets in the pancreas.

Anterograde transport of B-CT-FITC was examined in surviving preparations in vitro to confirm that enteric neurons proj- 

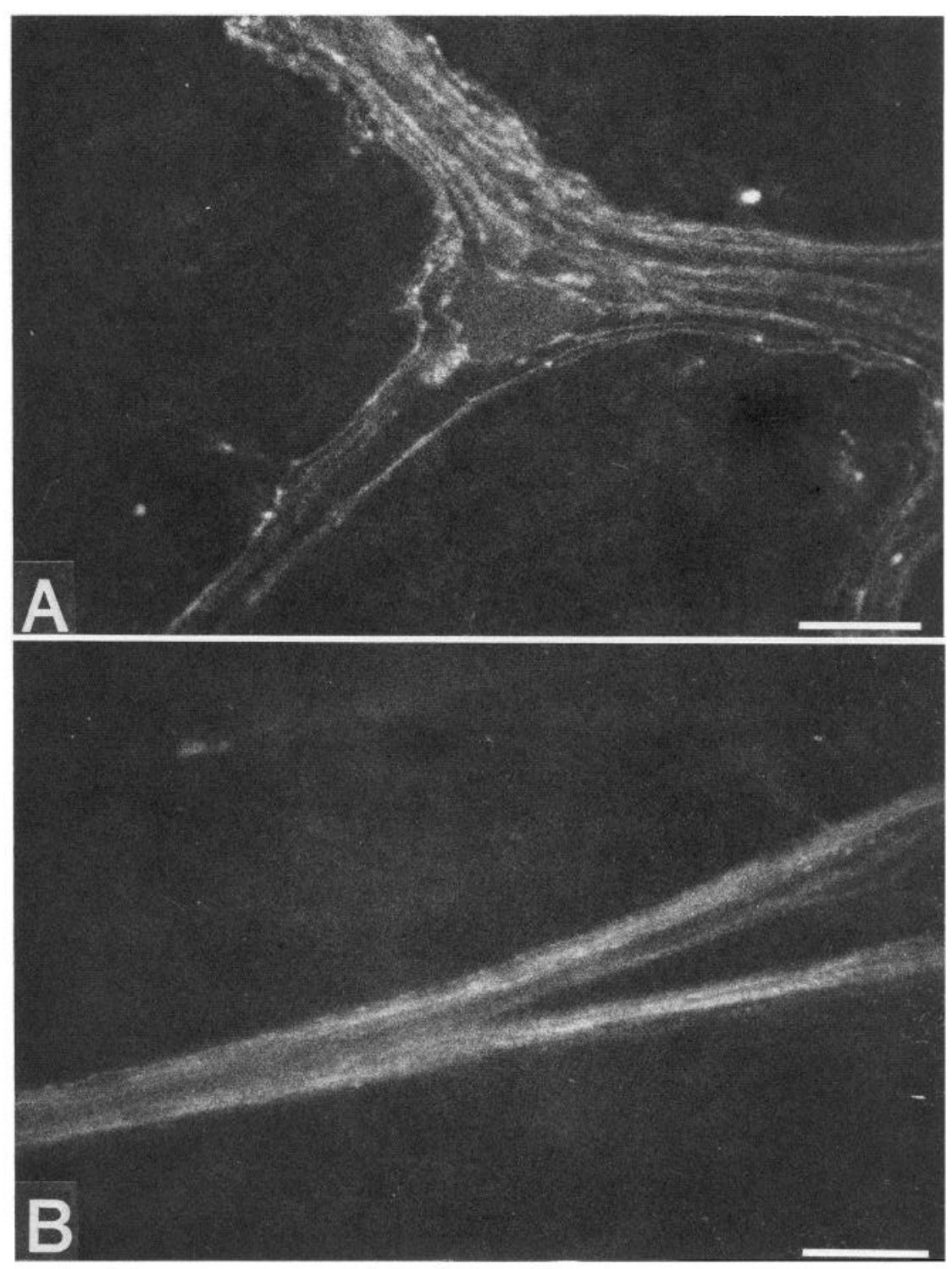

Figure 6. 5-HT immunofluorescent nerve fibers in ganglia of the myenteric plexus are varicose, whereas those in entero-pancreatic nerve bundles are not. $A$, 5-HT immunoreactivity demonstrated in a ganglion and connectives in the myenteric plexus of the duodenum. $B$, 5-HT immunoreactivity in nerve bundles in the connective tissue between duodenum and pancreas. Scale bars, $50 \mu \mathrm{m}$. ect to the pancreas. The tracer was miroinjected into individual myenteric ganglia of the duodenum. Four hr were allotted for axonal transport to the pancreas. The fluorescence of B-CTFITC enabled the injections to be monitored as they were made so that spread beyond the confines of a ganglion could be avoided. The tracer was visualized in the pancreas by immunocytochemistry. Within the pancreas immunoreactive B-CT was found in thick nerve bundles in connective tissue septae (Fig. 10A), in axons that followed blood vessels (Fig. 10B), as smaller nerves that peeled off the main nerves to enter the pancreatic parenchyma (Fig. 10A), in terminals abutting upon pancreatic ganglion cells (Fig. 10C), and less commonly, apparently contacting insulin immunoreactive islet cells (Fig. 10, D-F).

\section{Enteric activation of the pancreas}

In vitro experiments were done in order to determine whether enteric neurons can directly affect pancreatic activity. Veratridine $(10 \mu \mathrm{M})$ was placed into the duodenal lumen in order to excite enteric neurons. Cytochrome oxidase activity was demonstrated histochemically in enteric and pancreatic neurons as well as in pancreatic acini and islets. Intraluminal veratridine increased the mean density of the cytochrome oxidase reaction product in both myenteric (Fig. $11 A$ ) and intrapancreatic neurons (Figs. $11 B ; 12, A, B$ ) above that seen in either control. The inclusion of TTX $(1.0 \mu \mathrm{M})$ in the duodenal lumen with veratridine reduced the level of cytochrome oxidase activity in myenteric neurons below that seen when the duodenal lumen was filled only with Krebs solution (Fig. 11 $A$ ); however, this effect of luminal TTX was not seen in the pancreas. There was no significant difference in the cytochrome oxidase activity of pancreatic neurons between preparations in which the duodenum was filled only with Krebs solution and those in which the duodenum was filled with veratridine and TTX (Fig. 11B). The effect of veratridine on intrapancreatic neurons was inhibited by a partial myectomy (in which a portion of the myenteric plexus was mechanically removed from the duodenum) and by adding the nicotinic antagonist hexamethonium $(10 \mu \mathrm{M})$ to the solution outside the bowel in which the gut and pancreas were suspended (Fig. 11B). Hexamethonium also prevented the activation of myenteric neurons by intraluminal veratridine (Fig. $11 B$ ). Like TTX, hexamethonium reduced the activity of cytochrome oxidase in myenteric neurons below that seen in prep- 


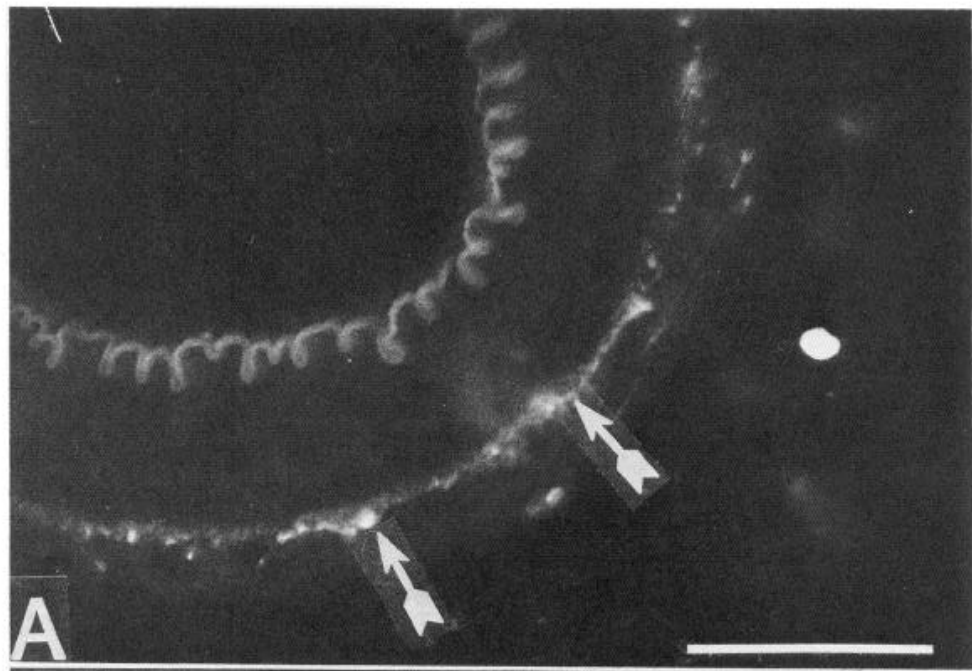

Figure 7. Varicose 5-HT immunoreactive axons, but not nerve cell bodies, are found in the pancreatic stroma and parenchyma. $A$, Rat pancreas. 5-HT immunoreactive nerve fibers $(\rightarrow)$ at the junction of the adventitia and the media of an artery. $B$, Guinea pig pancreas. 5 -HT immunoreactive axons $(\rightarrow)$ within a large nerve bundle in a connective tissue septum. An isolated 5-HT immunoreactive non-neuronal cell $(\vec{C})$ can also be seen adjacent to acini. $C$, Guinea pig pancreas. Fine varicose 5 -HT immunoreactive axons wind between acini. Scale bars, $50 \mu \mathrm{m}$.
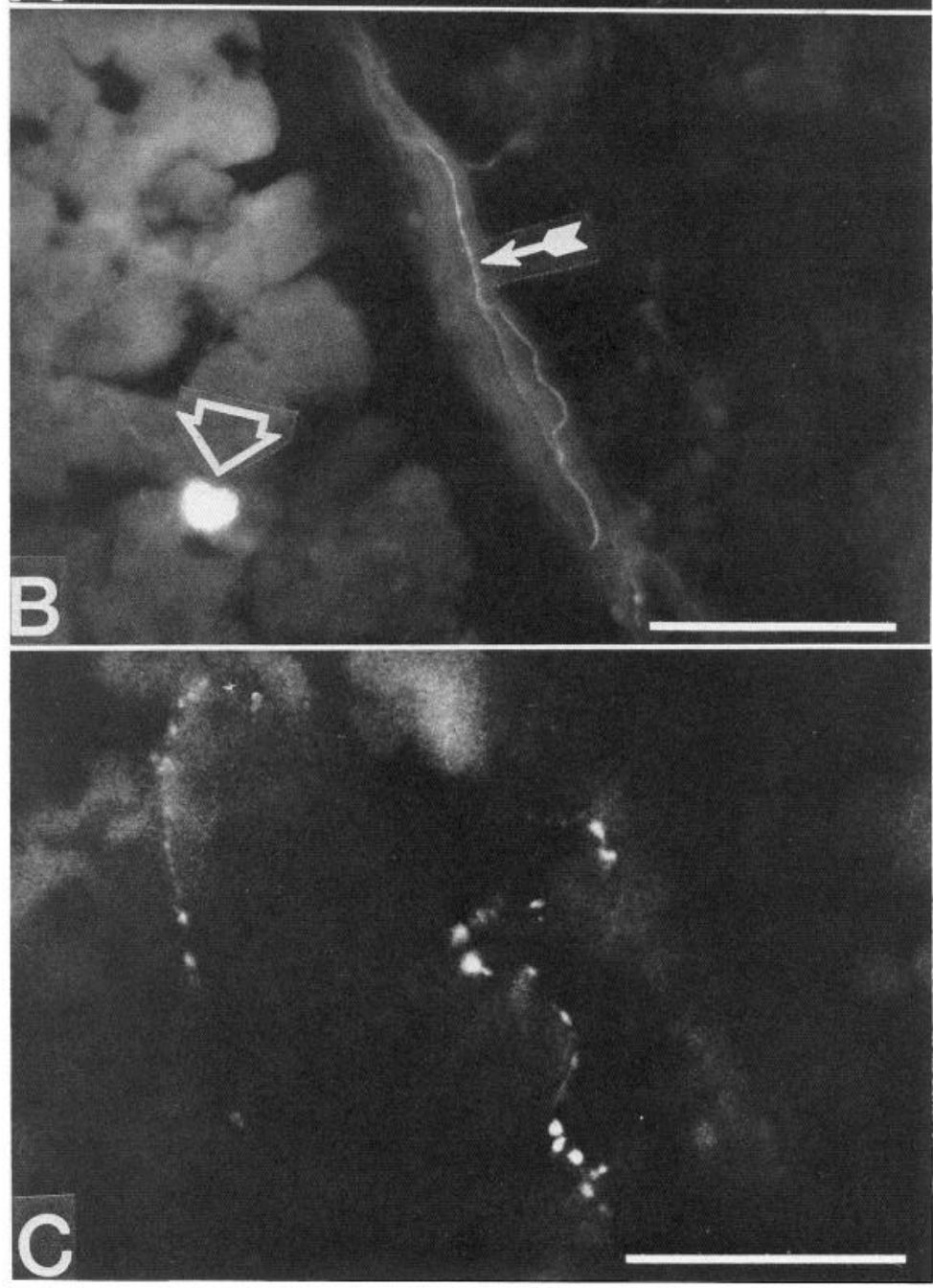

arations filled only with Krebs solution, although the decrement was significantly less for hexamethonium than for TTX. In parallel with the excitation of pancreatic neurons, the intraduodenal application of veratridine also was found to increase the cytochrome oxidase activity of pancreatic acinar (Figs. $11 C ; 12, A$, $B$ ) and islet cells (Figs. $11 D ; 12, C, D$ ). These effects also were inhibited by partial myectomy and blocked by intraluminal TTX or addition of hexamethonium to the external medium. The pancreatic actions of intraduodenal veratridine were heteroge- neous. Some areas of the pancreas appeared to be unaffected by the treatment. Measurements were made from the affected regions.

\section{Discussion}

The hypotheses were tested that enteric neurons project to the pancreas and can influence pancreatic exocrine and endocrine function. Precedent for an innervation by the ENS of extraen- 

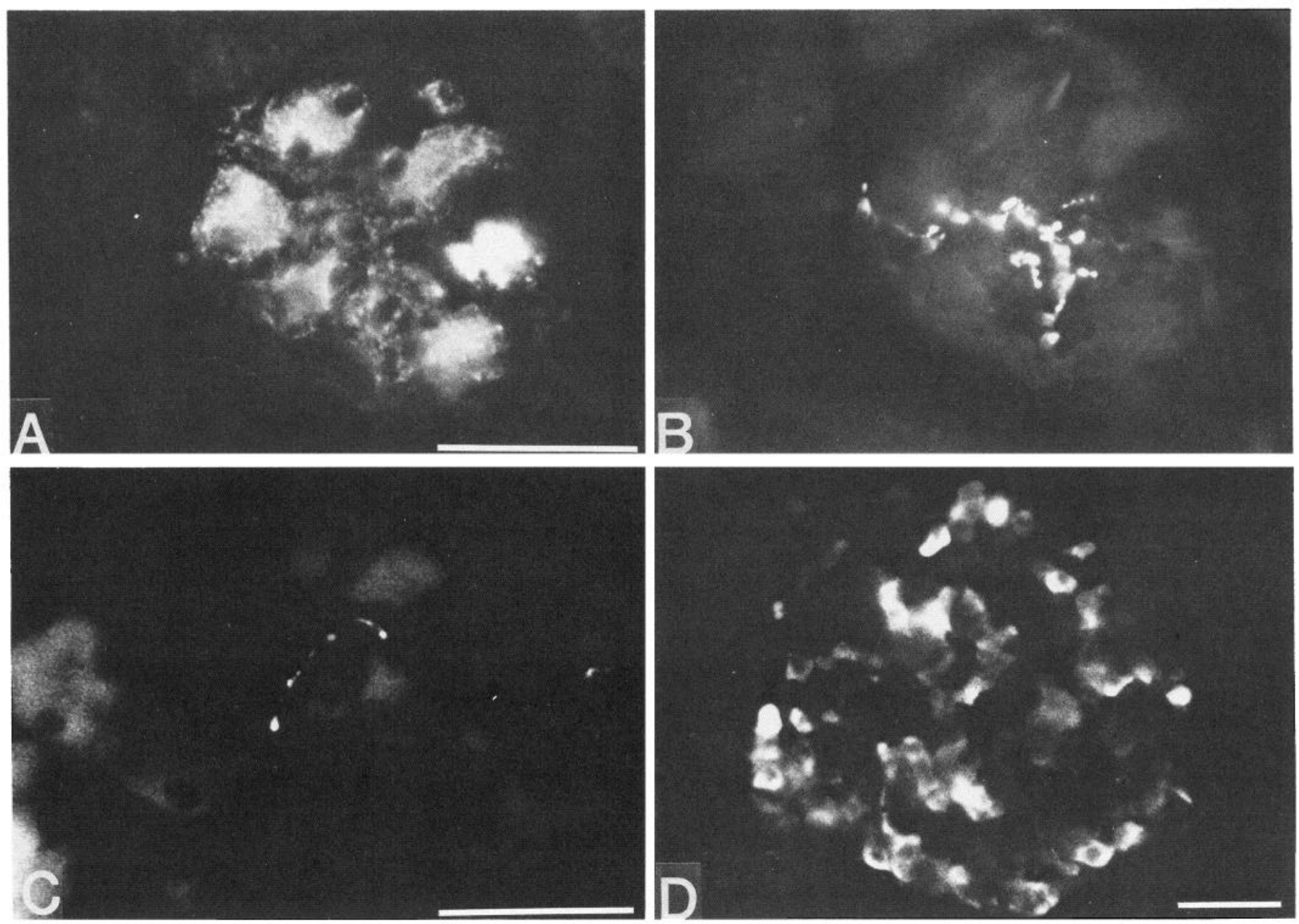

Figure 8. Varicose 5-HT immunoreactive axons are found in pancreatic ganglia and islets. Guinea pig pancreas. $A$, All neurons in a pancreatic ganglion express MAO-B immunoreactivity. The " $\mathrm{L}_{2}$ " filter cube is used to visualize FITC fluorescence. $B$, 5-HT immunoreactivity. The same ganglion illustrated in $(A)$ is again shown, but illuminated with the " $\mathrm{N}_{2}$ " filter cube to visualize TRITC fluorescence. Note the varicose 5-HT immunoreactive axons apparently contacting neurons that do not contain 5-HT. $C$, Varicose 5-HT immunoreactive axons at the periphery of an islet of Langerhans. $D, 5$-HT immunoreactivity displayed by islet cells. Scale bars, $50 \mu \mathrm{m}$.

teric structures exists in that enteric neurons have been demonstrated to innervate prevertebral ganglia (Ungváry and Léránth, 1970; Szurszewski and Weems, 1976; Dalsgaard et al., 1983; Lee et al., 1986; Furness and Costa, 1987) and the ganglionated plexus of the gallbladder (Mawe and Gershon, 1989). Previous observations compatible with the idea that axons derived from neurons resident in the enteric plexuses enter the pancreas include the presence of nerves in the connective tissue between gut and pancreas (Tiscornia, 1977; Anglade et al., 1987) and the presence within the pancreatic parenchyma of axons, but not nerve cell bodies, that specifically concentrate ${ }^{3} \mathrm{H}-5-\mathrm{HT}$ (Koevary et al., 1980, 1983; Nunez et al., 1980). The specific uptake of ${ }^{3} \mathrm{H}-5-\mathrm{HT}$ by pancreatic axons suggests that these fibers are serotonergic. The serotonergic neural phenotype is rare in the PNS, but is found in the ENS (Furness and Costa, 1987; Gershon et al., 1989) and the gallbladder (Mawe and Gershon, 1989). It is thus possible that enteric serotonergic neurons send axonal projections to the pancreas. Hypotheses were initially tested by determining with appropriate tracers and examination of nerve fibers in whole mounts if the postulated neural pathway leading from the bowel to the pancreas exists. When evidence for the presence of such a pathway was found, additional ex- periments were carried out to determine if stimulation of enteric neurons could alter the activity of pancreatic neurons, acinar, or islet cells.

Examination of whole mounts of tissue in which AChE activity was histochemically demonstrated confirmed the existence of nerves running between duodenum and pancreas. These nerves were found to be continuous with the myenteric plexus of the duodenum and with pancreatic ganglia. Although these nerves provide a potential pathway for an enteric innervation of the pancreas, the observations do not by themselves confirm that enteric neurons project to pancreatic targets. Conceivably, autonomic or sensory fibers could traverse the duodenum before entering the pancreas (or the reverse); moreover, the visualization of nerve fibers in whole mounts does not establish in which direction the fibers run. Retrograde and anterograde tracing techniques were therefore utilized.

Injections of Fluoro-Gold into the pancreas labeled the perikarya of neurons in ganglia within the pancreas and in the myenteric plexus of the stomach and duodenum. It is likely that this labeling, both in the bowel and in the pancreas, was due to the retrograde transport of Fluoro-Gold. Fluoro-Gold was observed in pancreatic nerve fibers, thereby demonstrating that nerves 


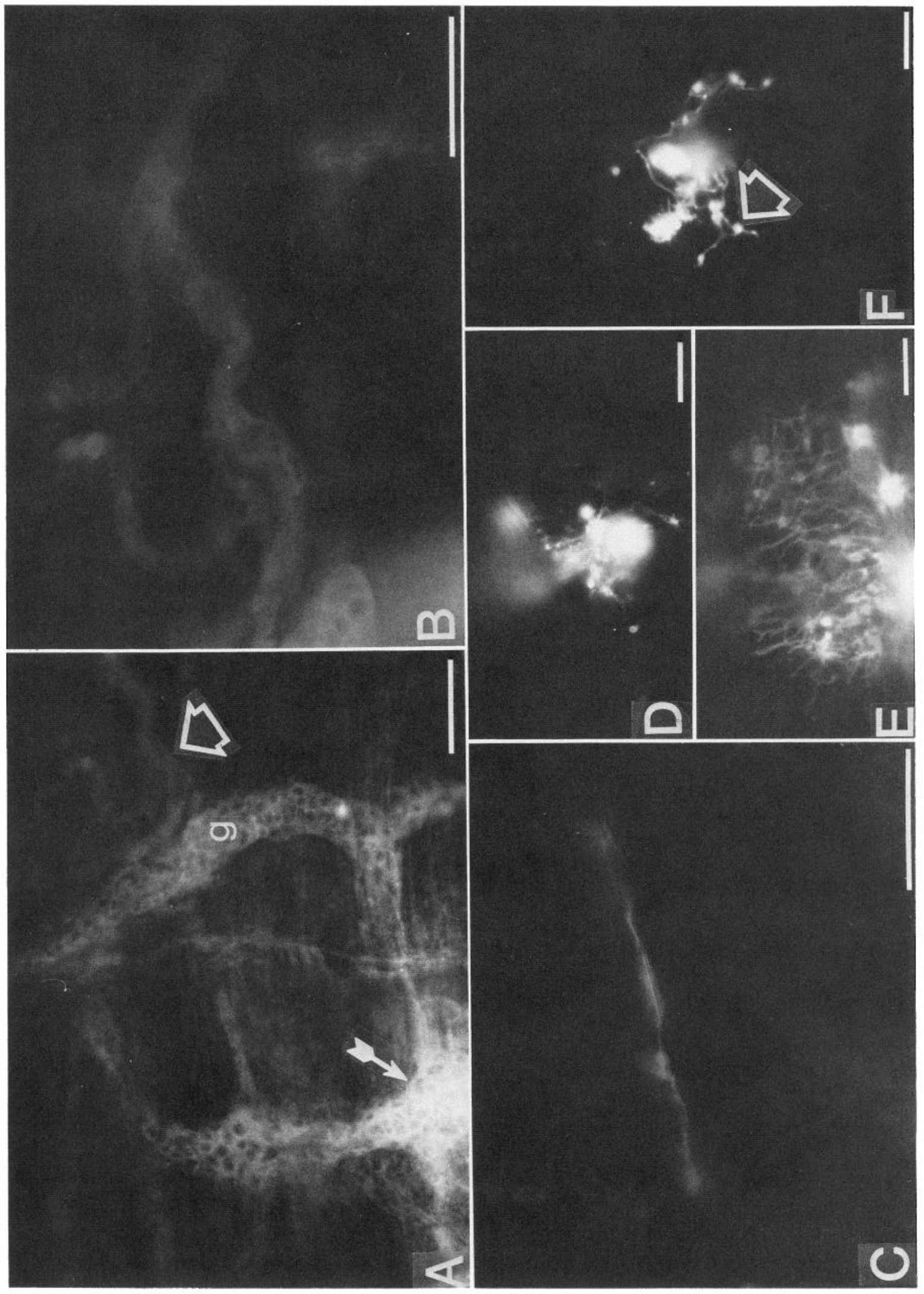

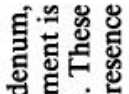

등

可

त क है

政

$x$ 的

늘

o a

एँ

당

它它

ส]

엉

항 명 o

政

잉

든

을

政

․ㅝㅇㅇ

of

कि

든

敬

4동

등을 도늘

(

䒱

등

政

当

.?

등

을.

긍도

$\Rightarrow$

吼

绕

응 당

跣

次

च

के

츨

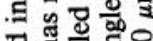

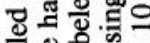

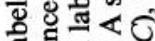

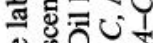

क्षे

象的

로용ㅇ

믈

过

엉 원

흐믐

. $\Xi$ 巴

웅.

责

늘

$\alpha$ 등 है

뭉

†

款白 

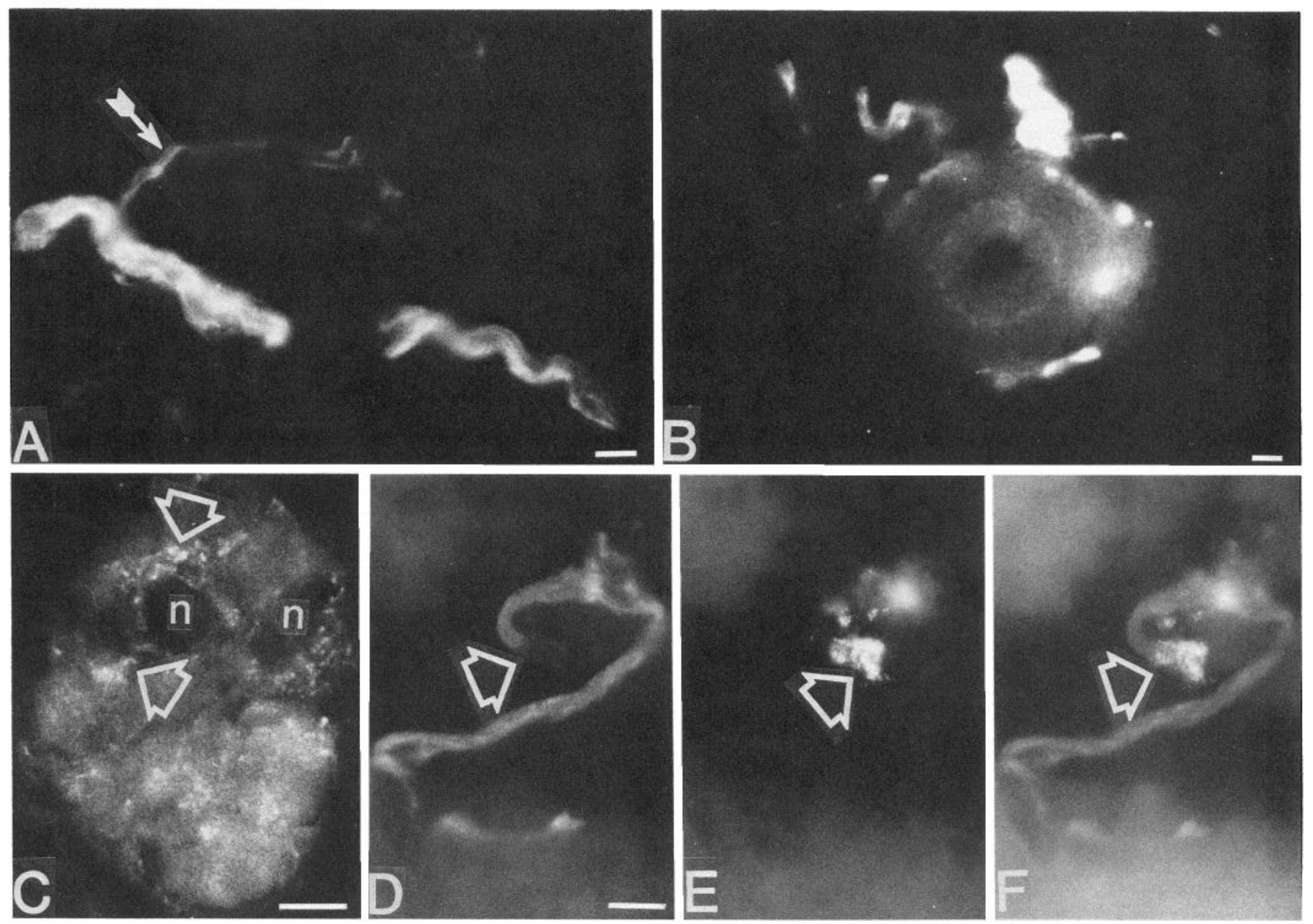

Figure 10. Entero-pancreatic nerves are labeled following the microinjection of B-CT into single ganglia of the duodenal myenteric plexus. A, A nerve bundle in a connective tissue septum of the guinea pig pancreas shows B-CT immunoreactivity. A smaller group of B-CT immunoreactive fibers $(\rightarrow)$ leaves the main nerve to enter the pancreatic parenchyma. $B$, B-CT immunoreactive nerve fibers are found in the connective tissue near a pancreatic artery and within the vessel at the junction of the media and the adventitia. $C$, Fine B-CT immunoreactive nerve endings $(\Delta)$ encircle nonfluorescent neurons $(n)$ in a pancreatic ganglion. $D-F$, The same field is illustrated in each figure; a B-CT immunofluorescent nerve appears to contact an insulin immunoreactive cell. $D$, The " $\mathrm{L}_{2}$ " filter cube is used to visualize FITC fluorescence. Only B-CT immunoreactivity is visible, but the $(\Rightarrow)$ marks the position of an insulin immunoreactive cell. $E$, The " $\mathrm{N}_{2}$ " filter cube is used to visualize TRITC fluorescence. The insulin immunoreactive cell noted in $(D)$ can now be seen $(B) . F$, A double exposure permitting both the B-CT immunoreactive nerve and the insulin immunoreactive cell $(\Delta)$ to be simultaneously visualized. Scale bars, $10.0 \mu \mathrm{m}$.

did take up the tracer. Moreover, no labeling of enteric neurons was seen if insufficient time for retrograde transport was allowed, and no fluorescence was seen in the longitudinal muscle of the bowel through which Fluoro-Gold diffusing from pancreas to the myenteric plexus would have to travel. In contrast, when Fluoro-Gold was placed on the surface of the pancreas, the neighboring intestinal musculature immediately became fluorescent. Most of the pancreatic ganglia that were labeled by Fluoro-Gold were not included in the injection sites. As was true of enteric ganglia, these ganglia also displayed punctate intracellular Fluoro-Gold fluorescence when no fluorescence was apparent in the surrounding tissue. This pattern suggests that Fluoro-Gold was taken up by the terminals of intrapancreatic neurons and labeled nerve cell bodies in pancreatic ganglia, not by direct spread of Fluoro-Gold through tissue but by retrograde transport. Moreover, although pancreatic injections of FluoroGold labeled neurons in the dorsal motor nucleus of the vagus, confirming that the tracer was taken up and transported in the retrograde direction by the intrapancreatic terminals of vagal axons, no Fluoro-Gold fluorescence was detected in phrenic motor neurons or in the nucleus ambiguous. If Fluoro-Gold had diffused out of the pancreas into the peritoneal cavity, it would have reached the diaphragm and/or gastroesophageal junction (Fox and Powley, 1986; Rinaman and Miselis, 1987). FluoroGold reaching these sites would be taken up by phrenic or vagal terminal axons respectively, and label the perikarya of the neurons in the cervical spinal cord and brainstem from which these axons originate. Finally, the punctate appearance of the fluorescence of Fluoro-Gold in the cell bodies of the neurons it labeled is the appearance that would be expected if Fluoro-Gold had entered these perikarya by retrograde transport and had been sequestered in lysosomes. Observations made with FluoroGold, therefore, provide strong support for the hypothesis that enteric neurons, as well as neurons in the dorsal motor nucleus of the vagus, provide an efferent innervation to the pancreas.

Further support for the idea that the ENS projects to the pancreas was obtained from experiments with the intercalating dye Dil. Following its microinjection into single myenteric gan- 

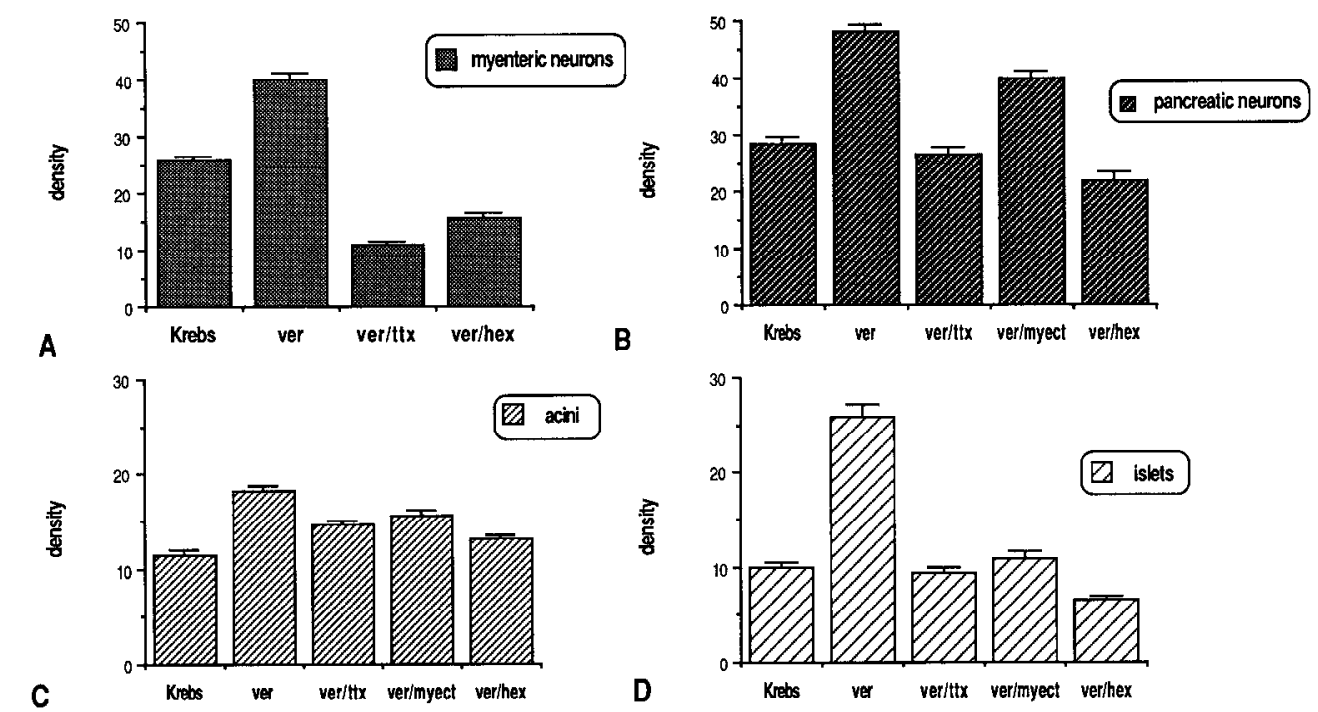

Figure 11. Cytochrome oxidase reaction product density in neurons of myenteric and pancreatic ganglia and in pancreatic acinar and islet cells following the intraluminal exposure of the duodenum to veratridine. $A$, Neurons of the myenteric plexus. Krebs, control; the lumen of the duodenum was filled only with Krebs solution; ver, veratridine $(10.0 \mu \mathrm{M})$ added to Krebs solution in the duodenal lumen; ver/ttx, veratridine (10.0 $\mu \mathrm{M})$ plus tetrodotoxin $(1.0 \mu \mathrm{M})$ added to Krebs solution in the duodenal lumen; ver/hex, veratridine $(10.0 \mu \mathrm{M})$ plus hexamethonium $(10.0 \mu \mathrm{M})$ added to the Krebs solution outside the duodenum. All groups differ significantly from one another $(p<0.01)$. B, Pancreatic ganglia. ver/myect, veratridine $(10.0 \mu \mathrm{M})$ added to Krebs solution in the lumen of a segment of duodenum that has been subject to a partial myectomy; other groups as in $(A)$. ver is significantly greater than Krebs, ver/myect, ver/ttx, and ver/hex $(p<0.01)$; differences betwecn Krebs, ver/ttx, and ver/hex are not significant; $v e r / m y e c t$ is significantly greater than ver/ttx or ver/hex. $C$, Pancreatic acinar cells. ver is significantly greater than $\mathrm{Krebs}$, ver/ttx, ver/myect, and ver/hex $(p<0.01)$. D, Pancreatic islet cells. ver is significantly greater than Krebs, ver/ttx, ver/myect, and ver/hex $(p<0.01)$.

glia in fixed preparations of duodenum with attached pancreas, movement of the dye could be followed temporally. Dil was observed to move away from the ganglion into which it was injected. Dil diffused first along interganglionic connectives within the duodenal myenteric plexus to reach adjacent and then progressively more distant ganglia. Dil was then seen to lcave the myentcric plexus in nonvaricose nerves that traversed the longitudinal muscle to enter the connective tissue between the duodenum and the pancreas. Finally, after about a month, Dil was found in the terminal arbors of nerves within the pancreatic parenchyma. Unfortunately, it was not possible to identify the intrapancreatic structures innervated by the Dil labeled enteric axons since the Dil containing tissue could not be sectioned. Anterograde labeling of enteric nerve terminals in the pancreatic parenchyma was therefore confirmed by another technique, the microinjection of B-CT into individual myenteric ganglia. Myenteric ganglia are very small, containing about 100 neurons/ganglion in the guinea pig small intestine (Takaki et a1., 1985). It is thus difficult to confine most tracers to individual ganglia. Nevertheless, the B component of CT binds tightly to ganglioside $\mathrm{Gm}_{1}$ on cell surfaces (Gill, 1977) and remains highly localized following its injection into tissue (Takaki et al., 1985). Moreover, the B-CT injected in the current experiments was itself coupled to FITC; therefore, the distribution of the tracer could be directly monitored during the injections and kept from spreading beyond the confines of a ganglion. B-CT has been extensively used as a retrograde tracer which can be detected with great sensitivity by immunocytochemistry (Luppi et al., 1988). The probe evidently also moves in the anterograde direction, although this movement could not be observed until B-CT immunoreactivity was demonstrated. The native fluorescence of B-CT-FITC was not adequate to visualize the tracer in nerve terminals. When myenteric ganglia were microinjected with B-CT-FITC, B-CT immunoreactive nerve fibers were found individually and in bundles within the pancreatic parenchyma and in the adventitia of intrapancreatic blood vessels. B-CT immunoreactive terminals were most commonly observed in pancreatic ganglia, but were also found in close apposition to insulin immunoreactive cells. The appearance of B-CT immunoreactive terminals, encircling a subset of neurons in pancreatic ganglia, suggests that these neurons are targets of an entero-pancreatic innervation. The observation that close appositions exist between B-CT labeled axons from the gut and acinar and insulin containing cells, however, does not establish that these apparent contacts are functional synapses. Autonomic terminals are nondirectional (Gershon et al., 1985) and often located at a considerable distance from the cells they innervate (Burnstock et al., 1979), thus making it impossible to identify the innervated partner at autonomic neuroeffector junctions, even by electron microscopy. As a result, the observations that B-CT immunoreactive axons enter islets or pass close to acini, do not by themselves establish that either of these structures is actually innervated by enteric neurons. Nevertheless, our observations with Fluoro-Gold, Dil, and B-CT are mutually supportive, and taken together, do establish that the pancreas receives an enteric innervation. Moreover, since studies of anterograde transport in 2 species (rat as well as guinea pig) both suggest that enteric neurons innervate pancreatic targets, it seems reasonable to conclude that this projection is not limited to the guinea pig.

A subset of the enteric neurons labeled by retrograde transport of Fluoro-Gold also took up 5,7-DHT and were 5-IIT immunoreactive. Moreover, 5-HT immunoreactive axons were found in the pancreas. These results support the proposal (Nunez et 


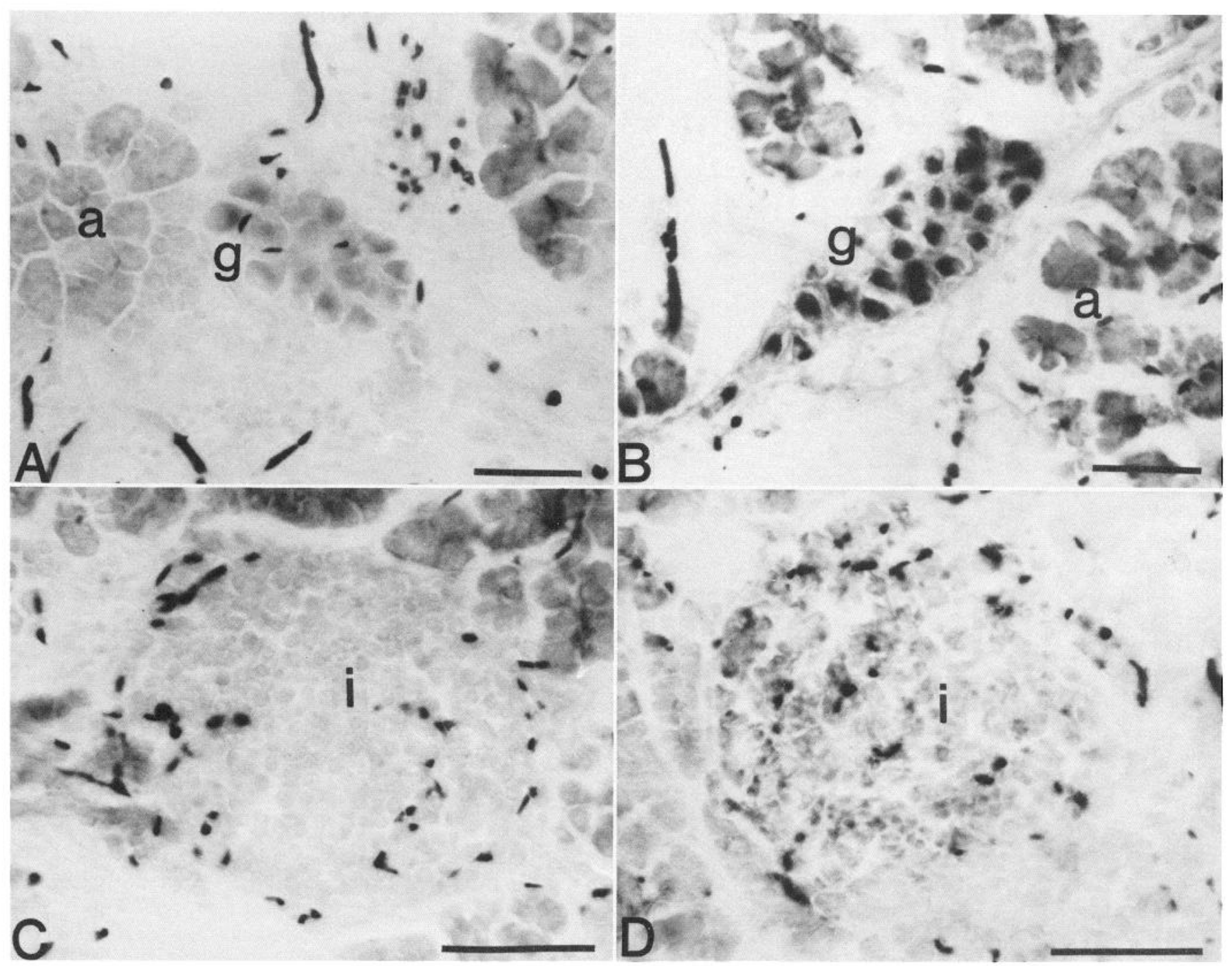

Figure 12. Intraluminal exposure of the duodenum to veratridine in vitro increases histochemically demonstrated cytochrome oxidase activity in neurons, acinar, and islet cells in sections of attached pancreas. $A, C$, Controls; the lumen of the duodenum was filled only with Krebs solution. $g$, ganglion; $a$, acini; $i$, islet. $B, D$, The lumen of the duodenum contained veratridine $(10.0 \mu \mathrm{M})$. Scale bars, $50.0 \mu \mathrm{m}$.

al., 1980; Koevary et al., 1980, 1983) that there are serotonergic nerve fibers in the pancreas. The triple labeling of enteric serotonergic neurons with Fluoro-Gold and 5,7-DHT or anti-5-HT sera indicates that at least some of the pancreatic serotonergic axons are derived from the ENS. Since no 5-HT immunoreactive nerve cell bodies were observed in the pancreas, it is possible that all of the intrapancreatic serotonergic axons originate in the bowel. This possibility was not confirmed; however, thick bundles of 5-HT immunoreactive nerve fibers were found to leave the myenteric plexus and, like the axon bundles labeled by Dil, to pierce the longitudinal muscle in the direction of the pancreas. Since these fiber bundles (both those demonstrated to be 5-HT immunoreactive and those that were Dil fluorescent) were nonvaricose they were probably fibers of passage. In contrast, the terminals of serotonergic axons within the myenteric plexus were varicose as were the ramifications of serotonergic axons within the pancreatic parenchyma. If the pancreatic serotonergic axons all originate from myenteric neurons in the stomach and duodenum, then 5-HT immunoreactivity in the pancreas becomes a marker for axon terminals derived from the bowel.
Varicose 5-HT immunoreactive axons were found in pancreatic ganglia, islets, and in the vicinity of acini. On the other hand, since neurons were found in the myenteric plexus of both stomach and duodenum that neither took up 5,7-DHT, nor were 5-HT immunoreactive, it is clear that not all of the enteric neurons that project to the pancreas are serotonergic. Those which are not revealed by 5 -HT immunolabeling probably utilize a different neurotransmitter.

Physiological experiments were performed, both to determine whether the neural pathways demonstrate anatomically to connect the ENS and the pancreas are functional and to identify the pancreatic targets of the enteric innervation. The histochemical demonstration of cytochrome oxidase activity was used for these studies. In neurons, the density of the cytochrome oxidase reaction product has been shown to reflect the preexisting level of physiological activity of the cells in which it is measured (Mawe and Gershon, 1986; Wong-Riley, 1989). Furthermore, increases in the rate of discharge of action potentials of neurons are closely coupled to an accompanying rise in the activity of histochemically demonstrable cytochrome oxidase 
activity. The cytochrome oxidase technique is advantageous for evaluating the ability of enteric neurons to affect pancreatic cells because it permits the activity of many putative target cells to be assessed simultaneously. Moreover, since the procedure is histochemical, targets are unambiguously identified by direct microscopic observation. The application of veratridine to the duodenal lumen was utilized as a probe with which to activatc entero-pancreatic neural pathways. Veratridine at the concentration that was employed, $10.0 \mu \mathrm{M}$, has previously been shown to induce a repetitive discharge of action potentials in enteric neurons that is sustained for hours (Mawe and Gershon, 1986). Luminal application was chosen in order to stimulate the mucosal terminals of intrinsic afferent fibers and thus to simulate activation of intrinsic reflex pathways. Experiments were done in vitro in order to be certain that any changes that might be observed in the cytochrome oxidase activity of pancreatic cells in response to stimulating the duodenum with veratridine would not involve the CNS and to minimize the possibility such activation could be due to the release of intestinal hormones.

Intraduodenal veratridine increased the level of cytochrome oxidase activity in neurons in both the myenteric plexus of the duodenum and in ganglia within attached segments of pancreas. Since the increase in the level of cytochrome oxidase activity in all these ganglia was blocked by TTX, the effect of veratridine was evidently specific and due to its effect on voltage gated $\mathrm{Na}^{+}$ channels (Ohta et al., 1973; Catterall, 1980). The veratridine induced rise in the activity of cytochrome oxidase in these neurons was also prevented by adding hexamethonium to the solution outside the gut; therefore, the effect of veratridine involved a nicotinic cholinergic synapse. Since veratridine was applied to the mucosal surface of the bowel and its effects could be prevented by intraluminal TTX, it is likely that the treatment activated submucosal neurons, which are known to provide the predominant intrinsic innervation of the mucosa (Furness and Costa, 1987). Neurons of the submucosal plexus have been demonstrated to project to myenteric ganglia (Kirchgessner and Gershon, 1988). Since activation of myenteric ganglia was blocked by hexamethonium applied to the outside of the bowel, the cholinergic synapse critical to this action of hexamethonium is probably located within the myenteric plexus. A subset of submucosal neurons which contain $\mathrm{ACh}$ and substance $\mathrm{P}$ has been postulated to be sensory and to project to the myenteric plexus (Bornstein et al., 1989). Our data are compatible with the hypothesis that these cholinergic neurons are activated by intraluminal veratridine and transmit the signal to neurons in ganglia of the mycntcric plexus. Wc would expect synaptic transmission by submucosal cholinergic neurons to be blocked by hexamethonium.

It is conceivable that veratridine, when introduced to the lumen of the duodenum, could release a hormone, such as cholecystokinin or secretin, from enteroendocrine cells by a TTX sensitive mechanism. Such a hormone might mediate the activation of cytochrome oxidase in pancreatic cells; however, it seems improbable that in the absence of the circulation, a hormone could diffuse out of a loop of bowel in vitro and affect the activity of neurons in the myenteric plexus and pancreas. Moreover, the ability of hexamethonium to prevent the increase in cytochrome oxidase activity indicates that the response is not a direct effect of an enteric hormone on myenteric or pancreatic neurons. Finally, the fact that the effects of duodenal veratridine on pancreatic neurons are inhibited by partial destruction of the myenteric plexus, even when connections betwecn gut and pan- creas are left intact, further indicates that enteric neurons and not mucosal hormones are responsible for enteric activation of pancreatic cells. The ability of hexamethonium and partial myectomy to antagonize the effect also demonstrates that the increase in cytochrome oxidase in pancreatic cells is not due to the diffusion of veratridine from the duodenum to the pancreas.

In addition to ncurons, an increase in the level of cytochrome oxidase activity was also noted in pancreatic acinar and islet cells following application of veratridine to the duodenum. In contrast to neurons, where the level of cytochrome oxidase activity has been demonstrated to reflect the rate of discharge of action potentials, no evidence has yet been obtained to relate cytochrome oxidase activity to secretion by acinar or islet cells. Nevertheless, the change in the level of cylochrome oxidase activity that was demonstrated in these cells in response to duodenal veratridine does show that the gut can at least affect their metabolic activity. Moreover, since this metabolic change, like that seen in pancreatic neurons in response to duodenal veratridine, was blocked by intraluminal TTX, partial myectomy, and hexamethonium, it is probably mediated by nerves and not by gut hormones. Neither ablation of duodenal myenteric ganglia, nor addition of hexamethonium would be expected to antagonize hormonal effects on acinar or islet cells. Moreover, veratridine has been shown to have no direct action on acinar cells because these cells do not express voltage sensitive $\mathrm{Na}^{+}$ channels (Williams, 1981; Gallagher et al., 1981); therefore, the effect of duodenal veratridine on the cytochrome oxidase activity of acinar cells cannot be due to a direct action of veratridine itself diffusing from the duodenum to the pancreas. Furthermore, since the cholinergic nerve fibers that activate pancreatic acinar and islet cells act on muscarinic receptors for ACh (Gardner and Jensen, 1987; Solomon, 1987), the antagonism of the effect of duodenal veratridine by hexamethonium indicates that veratridine does not act on pancreatic neurons directly. If veratridine had affected pancreatic neurons directly and not via a nicotinic synapse, the resulting muscarinic activation of acinar cells would not have been abolished by hexamethonium.

The rise in cytochrome oxidase in the pancreatic parenchyma following duodenal veratridine was widespread in those areas of the pancreas that were affected. The entire organ would not have been expected to respond since gastric as well as duodenal neurons project to the pancreas. Our anatomical studies with Dil and B-CT revealed a predominant enteric projection to ganglia and relatively few enteric nerve fibers adjacent to acinar cells; therefore, enteric nerves probably do not directly activate pancreatic acinar cells, but do so indirectly via synapses in pancreatic ganglia, which serve to amplify the signal from the bowel. It is noteworthy that when TTX was added to the duodenal lumen with veratridine, the cytochrome oxidase activity of myenteric neurons was less than that seen when the duodenal lumen was filled only with Krebs solution. This observation suggests that there is a level of ongoing nervous activity in filled duodenal sacs that is abolished by TTX. A similar effect of TTX was not observed in pancreatic neurons, acinar, or islet cells, implying that in contrast to the veratridine stimulated activity, the ongoing activity in the duodenal sacs was not transmitted to the pancreas. These data suggest that there is a specificity to entero-pancreatic pathways and that only certain types of neural information may be transmitted from bowel to pancreas. The veratridine stimulated activity may have been detectable in the pancreas because the stimulus was applied to the mucosa where it triggered a physiological reflex. When hexamethonium was 
added to the bath of preparations that had been treated with veratridine, the cytochrome oxidase activity of myenteric neurons was again less than that seen when only Krebs solution was present in the duodenal lumen; however, the activity of cytochrome oxidase was significantly greater in the presence of hexamethonium than when TTX was added. This difference in effectiveness in antagonizing the veratridine induced rise in cytochrome oxidase activity between TTX and hexamethonium suggests, either that some myenteric neurons are directly stimulated by veratridine, or that some of the synapses responsible for activating myenteric neurons are noncholinergic. In contrast to the myenteric plexus, hexamethonium is as effective as TTX in blocking the action of duodenal veratridine on the pancreas. This obscrvation implies that cholinergic neurons alone are sufficient to transmit enteric activity to the pancreas. Thus the experiments provide no indication of what role may be played by the demonstrated enteric serotonergic innervation of the pancreas. The serotonergic axons, therefore, seem more likely to be involved in modulating, not transmitting, the enteric signal to the pancreas.

In summary, the current experiments demonstrate for the first time that the enteric nervous system can influence the activity of the pancreas. Although both the exocrine and endocrine portions of the pancreas are affected by the gut, it seems likely that the activity of neither is influenced predominantly by enteric nerves that terminate directly on acinar or islet cells. Instead, the primary target of the entero-pancreatic innervation appears to be pancreatic ganglia, which transmit the signal to the effectors. The neural transmission of signals from gut to pancreas appears to be primarily cholinergic; however, the presence of substantial numbers of entero-pancreatic serotonergic axons indicates that a more complicated regulatory function also exists. It is thus clear that pancreatic activity can be influenced by the bowel through at least 3 different mechanisms. One is endocrine, depending on the release of hormones from the gastrointestinal mucosa. Another is neural, involving centrally processed reflexes with an efferent arm that encompasses the vagus and/or sympathetic nerves (Singer et al., 1989). The third is the currently demonstrated direct entero-pancreatic pathway. It remains for future experiments to determine which (or which combinations) of these possible mechanisms is utilized by particular stimuli and the physiological role played by each.

\section{References}

Anglade, P., C. Michel, and C. Roze (1987) Intrinsic nerves of the pancreas after celiac and superior mesenteric ganglionectomy in rats: A morphologic study of acetylcholinesterase activity and catecholamine histofluorescence. Pancreas 2: 568-577.

Bannerman, P. G., R. Mirsky, K. R. Jessen, R. Timpl, and V. C. Duance (1986) Light microscopic immunolocalization of laminin, type IV collagen, nidogen, heparan sulphate proteoglycan and fibronectin in the enteric nervous system of the rat and guinea-pig. J. Neurocytol. 15: 733-743.

Bornstein, J. C., J. B. Furness, and M. Costa (1989) An electrophysiological comparison of substance P-immunoreactive neurons and other neurons in the guinea-pig submucous plexus. J. Autonom. Nerv. Syst. 26: 113-120.

Burnstock, G., T. Hökfelt, M. D. Gershon, L. L. Iversen, H. W. Kosterlitz, and J. H. Szurszewski (1979) Non-adrenergic, non-cholinergic autonomic neurotransmission mechanisms. Neurosci. Res. Bull. 17: 377-519.

Bülbring, E., and A. Crema (1958) Observations concerning the actions of 5-hydroxytryptamine on the peristaltic reflex. Br. J. Pharmacol 13: 444-457.

Bülbring, E., R. C. Y. Lin, and G. Schofield (1958) An investigation of the peristaltic reflex in relation to anatomical observations. Q. J. Exp. Physiol. 43: 26-37.

Catterall, W. A. (1980) Neurotoxins that act on voltage-sensitive sodium channels in excitable membranes. Annu. Rev. Pharmacol. Toxicol. 20: 15-43.

Costa, M., J. B. Furness, A. C. Cuello, A. A. J. Verhofstad, H. W. J. Steinbusch, and R. P. Elde (1982) Neurons with 5-hydroxytryptamine-like immunoreactivity in the enteric nervous system: Their visualization and reactions to drug treatment. Neuroscience $7: 351-$ 363.

Dalsgaard, C.-J., T. Hökfelt, M. Schultzberg, J. M. Lundberg, L. Terenius, G. J. Dockray, C. Cuello, and M. Goldstein (1983) Origin of peptide-containing fibers in the inferior mesenteric ganglion of the guinea pig: Immunohistochemical studies with antisera to substance $\mathrm{P}$, enkephalin, vasoactive intestinal polypeptide, cholecystokinin and bombesin. Neuroscience 9: 191-211.

Doerffler-Melly, J., and W. L. Neuhuber (1988) Rectospinal neurons: Evidence for a direct projection from the enteric to the central nervous system in the rat. Neurosci. Lett. 92: 121-125.

Fox, E. A., and T. L. Powley (1986) Tracer diffusion has exaggerated CNS maps of direct preganglionic innervation of pancreas. J. Auton. Nerv. Syst. 15: 55-69.

Furness, J. B., and M. Costa (1982) Neurons with 5-hydroxytryptamine-like immunoreactivity in the enteric nervous system: Their projections in the guinea-pig small intestine. Neuroscience $7: 341-$ 349.

Furness, J. B., and M. Costa (1987) The Enteric Nervous System, Churchill Livingston, New York.

Gabella, G. (1971) Glial cells in the myenteric plexus. Z. Naturforsch. 26: 244-245.

Gabella, G. (1987) Structure of muscles and nerves in the gastrointestinal tract. In Physiology of the Gastrointestinal Tract, 2 nd Ed., L. R. Johnson, ed., pp. 335-382, Raven, New York.

Gallagher, S., H. Sankaran, and J. A. Williams (1981) Mechanism of scorpion toxin-induced enzyme secretion in rat pancreas. Gastroenterology 80: 970-973.

Gardner, J. D., and R. T. Jensen (1987) Secretagogue receptors on pancreatic acinar cells. In Physiology of the Gastrointestinal Tract, 2nd Ed., L. R. Johnson, ed., pp. 1109-1127, Raven, New York.

Gershon, M. D. (1981) The enteric nervous system. Annu. Rev. Neurosci. 4: 227-272.

Gershon, M. D., G. M. Mawe, and T. A. Branchek (1989) 5-Hydroxytryptaminergic neurotransmission in the gut. In Cardiovascular Pharmacology of 5-Hydroxytryptamine: Prospective Therapeutic Applications, P. R. Saxena, D. I. Wallis, W. Wouter, and P. Bevan, eds., pp. 191-210, Kluwer Academic, The Netherlands.

Gershon, M. D., J. H. Schwartz, and E. R. Kandel (1985) Morphology of chemical synapses and patterns of interconnection. In Principles of Neural Science, 2nd Ed., E. R. Kandel and J. H. Schwartz, eds., pp. 132-147, Elsevier, New York.

Gill, D. M. (1977) Mechanism of action of cholera toxin. Adv. Cyclic Nucleotide Res. 8: 85-118.

Godement, P., J. Vanselow, S. Thanos, and F. Bonhoeffer (1987) A study in developing visual systems with a new method of staining neurones and their processes in fixed tissue. Development 101:697713.

Holst, J. J., S. L. Jensen, O. B. Schaffalitzky de Muckadell, and J. Fahrenkrug (1980) Secretin and vasoactive intestinal polypeptide in the control of the endocrine pancreas. Front. Hormone Res. 7 : 119-131.

Honig, M. G., and R. I. Hume (1986) Fluorescent carbocyanine dyes allow living neurons of identified origin to be studied in long-term cultures. J. Cell Biol. 103: 171-187.

Jessen, K. R., and R. Mirsky (1980) Glial cells in the enteric nervous system contain glial fibrillary acidic protein. Nature 286: 736-737.

Jessen, K. R., and R. Mirsky (1983) Astrocyte-like glia in the peripheral nervous system: An immunohistochemical study of enteric glia. J. Neurosci. 3: 2206-2218.

Johnson, G. D., and G. M. de C. Nogueira Araujo (1981) A simple method of reducing the fading of immunofluorescence during microscopy. J. Immunol. Meth. 43: 349-350.

Karnovsky, M. J., and L. Roots (1964) A "direct-coloring" thiocholine method for cholinesterases. J. Histochem. Cytochem. 12: 219-221.

Kirchgessner, A. L., and M. D. Gershon (1988) Projections of submucosal neurons to the myenteric plexus of the guinea pig intestine: 
In vitro tracing of microcircuits by retrograde and anterograde transport. J. Comp. Neurol. 277: 487-498.

Kirchgessner, A. L., and M. D. Gershon (1989) Identification of vagal efferent fibers and putative target neurons in the enteric nervous system of the rat. J. Comp. Neurol. 285: 38-53.

Kirchgessner, A. L., J. Dodd, and M. D. Gershon (1988) Markers shared between dorsal root and enteric ganglia. J. Comp. Neurol. 276: 607-621.

Koevary, S. B., E. C. Azmitia, and R. C. McEvoy (1983) Rat pancreatic serotonergic nerves: Morphologic, pharmacologic and physiologic studies. Brain Res. 265: 328-332.

Koevary, S. B., R. C. McEvoy, and E. C. Azmitia (1980) Specific uptake of tritiated serotonin in the adult rat pancreas: Evidence for the presence of serotonergic fibers. Am. J. Anat. 159: 361-368.

Langley, J. N. (1921) The Autonomic Nervous System, Part 1, Heffer, Cambridge.

Lee, Y., S. Shiosaka, N. Hayashi, and M. Tohyama (1986) The presence of vasoactive intestinal polypeptide-like immunoreactive structures projecting from the myenteric ganglion of the stomach to the celiac ganglion revealed by a double-labelling technique. Brain Res. 383: 392-394.

Luppi, P. H., K. Sakai, P. Fort, D. Salvert, and M. Jouvet (1988) The nuclei of origin of monoaminergic, peptidergic, and cholinergic afferents to the cat nucleus reticularis magnocellularis: A double-labeling study with cholera toxin as a retrograde tracer. J. Comp. Neurol. 277: $1-20$.

Mawe, G. M., and M.D. Gershon (1986) Functional heterogeneity in the myenteric plexus: Demonstration using cytochrome oxidase as a verified cytochemical probe of the activity of individual enteric neurons. J. Comp. Neurol. 249: 381-391.

Mawe, G. M., and M. D. Gershon (1989) Structure, afferent innervation, and transmitter content of ganglia of the guinea pig gallbladder: Relationship to the enteric nervous system. J. Comp. Neurol. 283: 374-390.

McIntyre, N., C. D. Holdsworth, and D. S. Turner (1964) New interpretation of oral glucose tolerance. Lancet 2: 672-673.

Nunez, E. A., P. Gershon, and M. D. Gershon (1980) Serotonin and seasonal variation in the pancreatic structure of bats: Possible evidence for serotonin axons in the gland. Am. J. Anat. 159: 361-368.

Ohta, M., T. Narahashi, and R. F. Keller (1973) Effects of veratrum alkaloids on membrane potential and conductance of squid and crayfish giant axons. J. Pharmacol. Exp. Ther. 184: 143-154.

Pintar, J. E., P. Levitt, J. I. Salach, W. Weyler, M. B. Rosenberg, and X.O. Breakefield (1983) Specificity of antisera prepared against pure bovine MAO B. Brain Res. 276: 127-139.

Poulsen, J., P. Delikaris, N. A. Lovgreen, and T. W. Schwartz (1983) Impaired pancreatic innervation after pyloric transsection in dogs. Scand. J. Gastroenterol. 18: 17-22.

Rinaman, L., and R. R. Miselis (1987) The organization of vagal innervation of rat pancreas using cholera toxin-horseradish peroxidase conjugate. J. Auton. Nerv. Syst. 21: 109-125.

Rothman, T. P., V. M. Tennyson, and M. D. Gershon (1986) Colonization of the bowel by the precursors of enteric glia: Studies of normal and congenitally aganglionic mutant mice. J. Comp. Neurol. 252: 493-506.

Sandell, J. H., and R. H. Masland (1986) A system of indoleamineaccumulating neurons in the rabbit retina. J. Neurosci. 6: 3331-3347.

Schmued, L. C., and J. H. Fallon (1986) Fluoro-Gold: A new fluorescent retrograde axonal tracer with numerous unique properties. Brain Res. 377: 147-154.

Schofield, G. (1968) Anatomy of muscular and neural tissues in the alimentary canal. In Handbook of Physiology, The Alimentary Canal, vol. 4, E. F. Code, ed., pp. 1579-1628, American Physiological Society, Washington, D.C.

Singer, M. V., W. Niebel, and H. Goebell (1989) Action of cutting the extrinsic nerves of the pancreas on the pancreatic enzyme response to intestinal stimulants: A short review. In Nerves and the Gastrointestinal Tract, M. V. Singer and H. Goebell, eds., pp. 205-212, Kluwer Academic, The Netherlands.

Solomon, T. E. (1987) Control of exocrine pancreatic secretion. In Physiology of the Gastrointestinal Tract, 2nd Ed., L. R. Johnson, ed., pp. 1173-1207, Raven, New York.

Szurszewski, J. H., and W. A. Weems (1976) A study of the peripheral input to and its control by postganglionic neurons of the inferior mesenteric ganglion. J. Physiol. 256: 541-556.

Takaki, M., J. D. Wood, and M. D. Gershon (1985) Heterogeneity of ganglia of the guinea pig myenteric plexus: An in vitro study of the origin of terminals within single ganglia using a covalently bound fluorescent retrograde tracer. J. Comp. Neurol. 235: 488-502.

Tamir, H., K. Liu, R. F. Payette, S. Hsiung, M. Adlersberg, E. A. Nunez, and M. D. Gershon (1989) Human medullary thyroid carcinoma: Characterization of the serotonergic and neuronal properties of a neuroectodermally-derived cell line. J. Neurosci. 9: 1199-1212.

Tiscornia, O. (1977) The neural control of exocrine and endocrine pancreas. Am. J. Gastroenterol. 67: 541-560.

Trendelenburg, P. (1917) Physiologische und pharmakologische Versuche über die Dünndarm Peristaltick. Naunyn-Schmiedegers Arch. Exp. Pathol. Pharmakol. 81: 55-129.

Unger, R. H., and A. M. Eisentraut (1969) Entero-insular axis. Arch. Intern. Med. 123: 261-266.

Ungváry, Gy., and Cs. Léránth (1970) Termination in the prevertebral abdominal sympathetic ganglia of axons arising from the local (terminal) vegetative plexus of visceral organs. Z. Zellforsch. 110: 185191.

Williams, J. A. (1981) Electrical correlates of secretion in endocrine and exocrine cells. Fed. Proc. 40: 28-134.

Wong-Riley, M. T. T. (1989) Cytochrome oxidase: An endogenous metabolic marker for neuronal activity. Trends Neurosci. 12:94-101. 